\title{
Characterization of Proanthocyanidin Oligomers of Ephedra sinica
}

\author{
Joanna Orejola, Yosuke Matsuo ${ }^{\mathbb{D}}$, Yoshinori Saito and Takashi Tanaka * \\ Department of Natural Product Chemistry, Graduate School of Biomedical Sciences, Nagasaki University, \\ 1-14 Bunkyo-machi, Nagasaki 852-8521, Japan; jjorejola@up.edu.ph (J.O.); y-matsuo@nagasaki-u.ac.jp (Y.M.); \\ saiyoshi@nagasaki-u.ac.jp (Y.S.) \\ * Correspondence: t-tanaka@nagasaki-u.ac.jp; Tel.: +81-95-819-2432
}

Received: 14 July 2017; Accepted: 3 August 2017; Published: 6 August 2017

\begin{abstract}
Ephedra sinica, an important plant in Chinese traditional medicine, contains a complex mixture of proanthocyanidin oligomers as major constituents; however, only the minor components have been chemically characterized. In this study, oligomers with relatively large molecular weights, which form the main body of the proanthocyanidin fractions, were separated by adsorption and size-exclusion chromatography. Acid-catalyzed degradation in the presence of mercaptoethanol or phloroglucinol led to the isolation of 18 fragments, the structures of which were elucidated from their experimental and TDDFT-calculated ECD spectra. The results indicated that (-)-epigallocatechin was the main extension unit, while catechin, the A-type epigallocatechin-gallocatechin dimer, and the A-type epigallocatechin homodimer, were identified as the terminal units. Among the degradation products, thioethers of gallocatechin with 3,4-cis configurations, a B-type prodelphinidin dimer, a prodelphinidin trimer with both A- and B-type linkages, and a prodelphinidin dimer with an $\alpha$-substituted A-type linkage were new compounds. In addition, a phloroglucinol adduct of an A-type prodelphinidin dimer, a doubly-linked phloroglucinol adduct of epigallocatechin, and a unique product with a flavan-3-ol skeleton generated by the rearrangement of the aromatic rings were also isolated.
\end{abstract}

Keywords: Ephedra sinica; proanthocyanidin; oligomer; thiolysis; phloroglucinolysis; TDDFT; ECD

\section{Introduction}

Ephedra sinica Stapf (Fam. Ephedraceae) is one of the most important plants in traditional medicine, and is used as a diuretic, antipyretic, diaphoretic, and for relieving a cough and asthma [1]. As the crude drug, it has an official monograph in both the Chinese and Japanese Pharmacopoeias, where it is standardized against the major alkaloids, ephedrine and pseudoephedrine [2]. Thus, the main emphasis is conventionally given to its alkaloidal content, despite the fact that this only constitutes about $0.7-0.8 \%$ of the whole plant $[3,4]$. Clearly, the motivation for this is the proven clinical effects of these alkaloids on the respiratory, central nervous, and cardiovascular systems [5]. However, many species of Ephedra have also been shown to contain significant amounts of proanthocyanidins [6]. Recently, many health benefits of foods and medicinal plants have been attributed to proanthocyanidins [7], and some of their biological activities, including hypotensive and vasorelaxant effects [8,9], improvement of the airway microenvironment in asthma [10], and the inhibition of inflammation and remodeling in murine models of chronic asthma [11], are responsible for the aforementioned activities of E. sinica, especially its respiratory and cardiovascular effects. A number of studies have shown that Ephedra spp. also display other biological activities that are not attributed to alkaloids, including antimicrobial [12,13], antioxidant [14], anti-inflammatory [15,16], immunosuppressive [17], antiviral [18], anti-invasive, antiangiogenic, antitumor [19], and cytotoxic [20] 
properties. The dimeric proanthocyanidins of E. sinica show cytotoxic activity against the tumor cell lines SGC-7901, HepG2, and HeLa [21]. In addition, a decrease in the uremic toxin parameters of rats was reportedly induced by the administration of proanthocyanidin oligomers of E. sinica [22,23].

As for the composition of the proanthocyanidins of E. sinica, monomeric flavan-3-ols [12,24] and dimeric proanthocyanidins with A-type linkages have been isolated [12,21,25-28]. The presence of prodelphinidin trimers and tetramers with A- and B-type linkages has also been shown [12]. However, these flavan-3-ols and proanthocyanidins are minor components of the total polyphenol content, and our preliminary HPLC and TLC analysis of the extract suggested that the main body of the polyphenols was a complex mixture of oligomers, detected as a broad hump on the HPLC baseline and at the origin of the TLC plate (Figure 1a). Thus, the present study aimed at characterizing these proanthocyanidin oligomers by acid-catalyzed degradation in the presence of nucleophilic agents, that is, 2-mercaptoethanol or phloroglucinol. The degradation involved the cleavage of the interflavan bonds under acidic conditions, generating flavan-3-ols from the terminal units and flavanyl-4 cations from the extension units, which were trapped by nucleophilic agents (Scheme 1) [29].

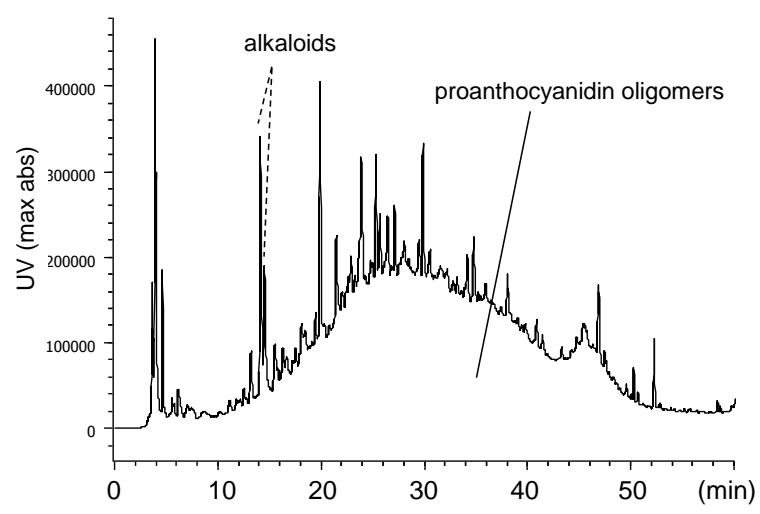

(a)

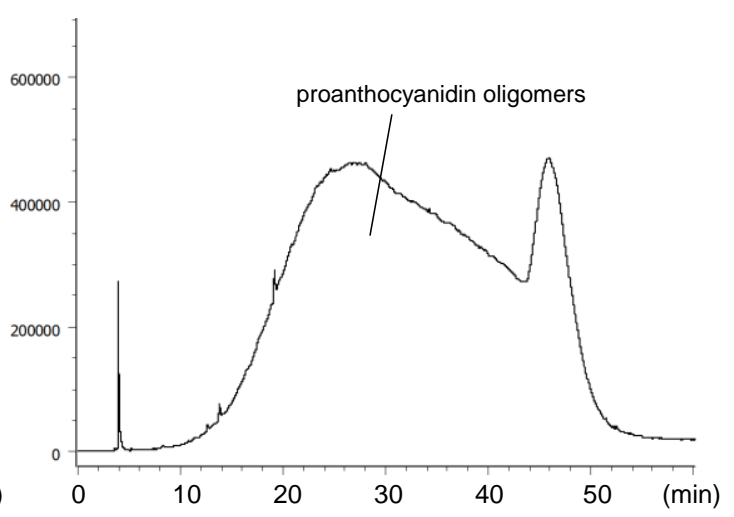

(b)

Figure 1. HPLC profiles of $60 \% \mathrm{EtOH}$ extract of E. sinica (a) and proanthocyanidin oligomer fraction (b).

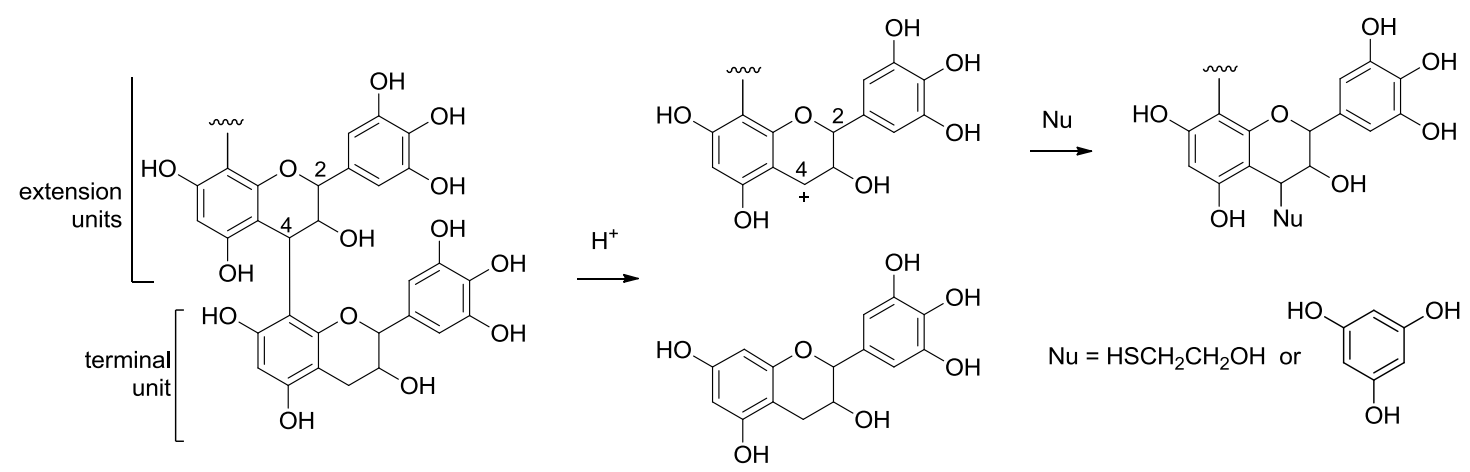

Scheme 1. Reaction mechanism of the acid-catalyzed cleavage of the interflavan bond in the presence of nucleophiles $(\mathrm{Nu})$.

\section{Results and Discussion}

\subsection{Composition of the Intact Proanthocyanidin Oligomer}

The dried aerial parts of E. sinica were extracted with aqueous acetone and fractionated by a series of chromatographic separation methods, including size-exclusion chromatography [30]. The fractions containing only oligomeric proanthocyanidins accounted for $2.7 \%$ of the dried plant material, and the HPLC profile showed a broad hump on the baseline (Figure $1 \mathrm{~b}$ ). The ${ }^{13} \mathrm{C}-\mathrm{NMR}$ spectrum of the oligomer fraction in DMSO- $d_{6}$ (Figure 2) showed signals characteristic of proanthocyanidins [31]. 
Based on a comparison with the literature data [11], the signals at $\delta_{C} 77$ and $\delta_{C} 70-73$, which were attributable to flavan C-ring C-2 and C-3 methine carbons, respectively, suggested the occurrence of B-type linkages. The chemical shifts also indicated that the 2,3-cis configuration was more abundant than 2,3-trans $[32,33]$. The signals in the range of $\delta_{C} 27-31$ were attributable to the C-4 carbons of A-type proanthocyanidin extension units [12] and of terminal units [34,35]. The prominent aromatic signals observed at $\delta_{C} 106,130,132$, and 145 suggested the predominance of pyrogallol-type B-rings over catechol-type B-rings $\left(\delta_{C} 115-120\right)$.

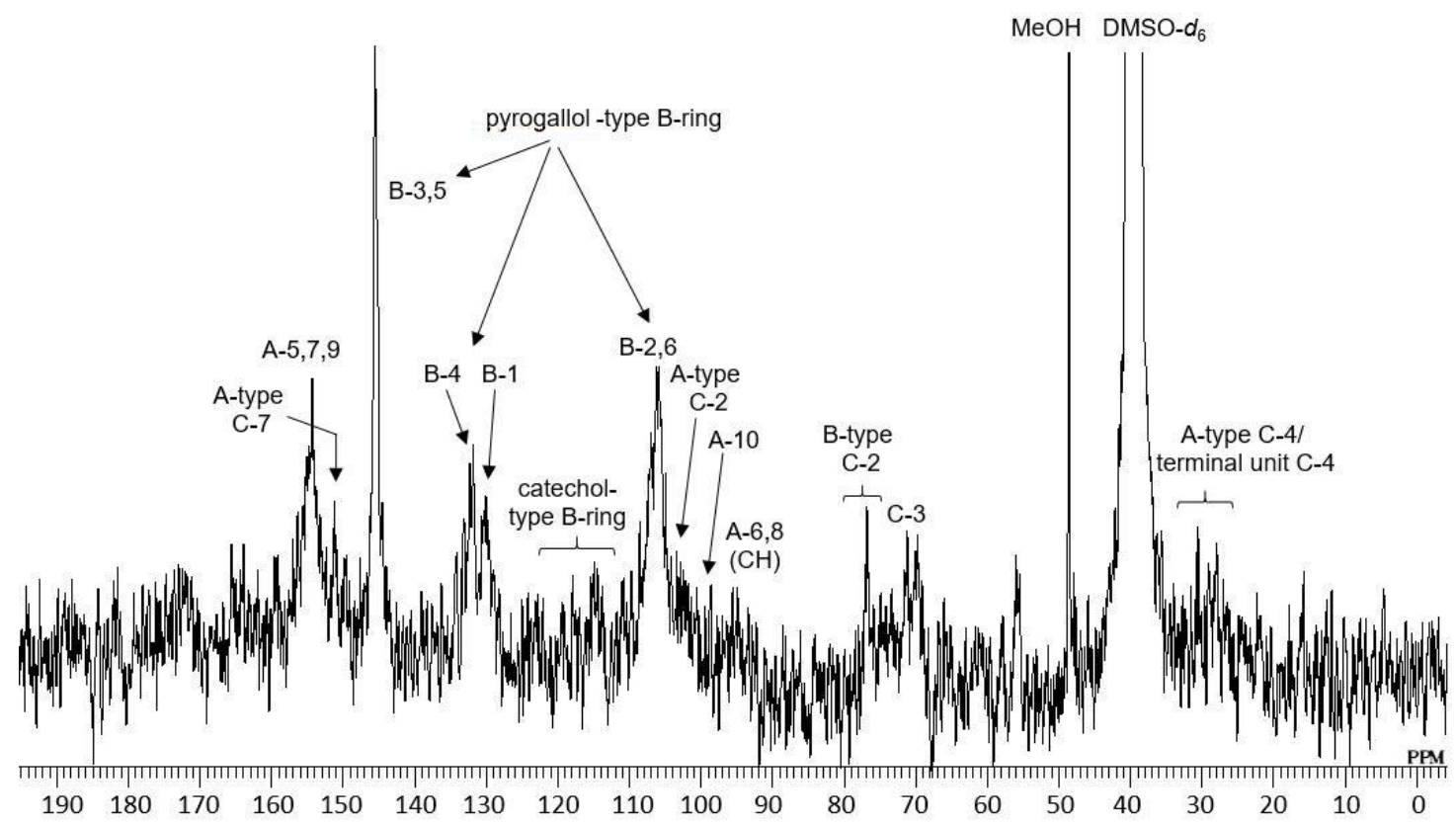

Figure 2. ${ }^{13} \mathrm{C}-\mathrm{NMR}$ spectrum of the proanthocyanidin oligomers from E. sinica, measured at $100 \mathrm{MHz}$ in DMSO- $d_{6}$.

\subsection{Acid-Catalyzed Degradation Products}

\subsubsection{Identification of Known Products}

Thiol degradation was performed according to the previously described method [35] with modifications of the reaction time and temperature, and 10 compounds (1-10) were isolated and characterized (Figure 3a). Acid-catalyzed degradation with phloroglucinol $[29,36]$ yielded a different set of 10 products $(\mathbf{5}, \mathbf{8}, \mathbf{1 1}-\mathbf{1 8})$, among which two products $(5$ and $\mathbf{8})$ were identical to those obtained by thiol degradation (Figure $3 b$ ).

Based on a comparison of the ${ }^{1} \mathrm{H}$ - and ${ }^{13} \mathrm{C}-\mathrm{NMR}$ data with those published [12,33], four products were identified as (+)-catechin (4), (-)-epigallocatechin- $(4 \beta \rightarrow 8,2 \rightarrow O \rightarrow 7)-(+)$-gallocatechin (5), (-)-epigallocatechin- $(4 \beta \rightarrow 8,2 \rightarrow O \rightarrow 7)-(+)$-catechin $\quad(8)$, and (-)-epigallocatechin- $(4 \rightarrow 8,2 \rightarrow O \rightarrow 7)$ (-)-epigallocatechin (17) (Figure 4). These products originated from the terminal units. As depicted in the HPLC profile of the reaction mixture (Figure 3), the peaks attributable to the terminal units were very small compared with those of the extension units, suggesting a high degree of polymerization. The major degradation products of thiolysis 6 and of phloroglucinolysis $\mathbf{1 2}$ were identified as epigallocatechin-nucleophile adducts $[33,37]$, indicating that epigallocatechin was the major extension unit of the oligomer. The ${ }^{1} \mathrm{H}$ - and ${ }^{13} \mathrm{C}-\mathrm{NMR}$ spectra of $\mathbf{9}, \mathbf{1 0}, \mathbf{1 1}, \mathbf{1 5}$, and 18 were found to be consistent with those previously reported for (-)-epigallocatechin- $(4 \rightarrow 8,2 \rightarrow O \rightarrow 7)$ (-)-epigallocatechin-4-(2-hydroxyethyl)-thioether, (-)-epicatechin-4-(2-hydroxyethyl)-thioether, (+)gallocatechin-4-phloroglucinol, (-)-epicatechin-4-phloroglucinol, and (+)-catechin-4-phloroglucinol, respectively $[33,37,38]$. 
<smiles>OCCS[C@H]1c2c(O)cc(O)c([C@H]3c4c(O)cc(O)cc4O[C@H](c4cc(O)c(O)c(O)c4)[C@@H]3O)c2O[C@H](c2cc(O)c(O)c(O)c2)[C@@H]1O</smiles><smiles>C[C@@H]1c2c(O)cc(O)cc2O[C@@H](c2cc(O)c(O)c(O)c2)[C@H](O)[C@@H]1SCCCO</smiles>

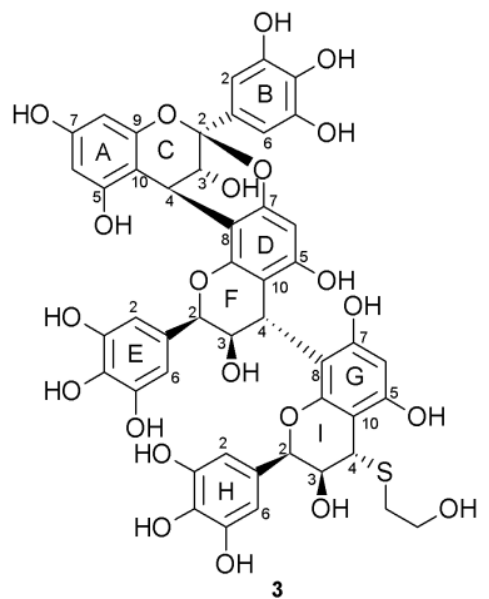

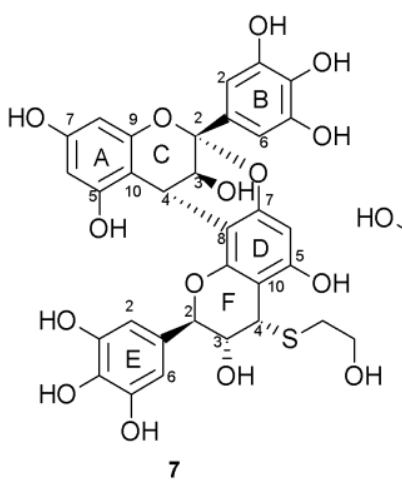<smiles>C[C@H](c1cc(O)c(O)c(O)c1)[C@@H]1Oc2cc(O)cc(O)c2[C@@H](c2c(O)cc(O)cc2O)O1</smiles>

Figure 5. Structures of the new products obtained by the thiolysis and phloroglucinolysis of E. sinica proanthocyanidin oligomers.

Table 1. ${ }^{1} \mathrm{H}-(500 \mathrm{MHz})$ and ${ }^{13} \mathrm{C}-(125 \mathrm{MHz}) \mathrm{NMR}$ data of $\mathbf{1}, \mathbf{2}, \mathbf{3}$, and 7 in acetone- $d_{6}$.

\begin{tabular}{|c|c|c|c|c|c|c|c|c|c|c|c|c|c|}
\hline \multirow{2}{*}{\multicolumn{2}{|c|}{ Position }} & \multicolumn{3}{|c|}{1} & \multicolumn{3}{|c|}{2} & \multicolumn{3}{|c|}{3} & \multicolumn{3}{|c|}{7} \\
\hline & & \multirow{2}{*}{$\frac{\delta_{\mathbf{H}}}{4.34}$} & \multirow{2}{*}{$\begin{array}{c}(\mathrm{J} \text { in } \mathbf{H z}) \\
\mathrm{d}(9.5)\end{array}$} & \multirow{2}{*}{$\frac{\delta_{\mathrm{C}}}{83.19}$} & \multirow{2}{*}{$\frac{\delta_{\mathrm{H}}}{4.77}$} & \multirow{2}{*}{$\begin{array}{c}(\mathrm{J} \text { in } \mathbf{H z}) \\
\mathrm{d}(9.7)\end{array}$} & \multirow{2}{*}{$\frac{\delta_{\mathrm{C}}}{78.77}$} & \multirow[t]{2}{*}{$\delta_{\mathrm{H}}$} & \multirow[t]{2}{*}{$(J$ in Hz) } & \multirow{2}{*}{$\frac{\delta_{\mathrm{C}}}{99.91}$} & \multirow[t]{2}{*}{$\delta_{H}$} & \multirow[t]{2}{*}{$(J$ in $\mathrm{Hz})$} & \multirow{2}{*}{$\begin{array}{c}\delta_{\mathrm{C}} \\
100.07\end{array}$} \\
\hline C & 2 & & & & & & & & & & & & \\
\hline & 3 & 4.50 & $\mathrm{dd}(7.8,9.5)$ & 73.26 & 4.07 & $\mathrm{dd}(9.7,4.4)$ & 71.59 & 4.20 & $\mathrm{~d}(3.4)$ & 67.31 & 4.15 & $\mathrm{~d}(3.6)$ & 66.82 \\
\hline \multirow[t]{4}{*}{ A } & 5 & & & 158.27 & & & 157.51 & & & 156.59 & & & 156.04 \\
\hline & 6 & 5.82 & s & 97.04 & 6.00 & $\mathrm{~d}(2.3)$ & 96.67 & 5.85 & $\mathrm{~d}(2.4)$ & 97.58 & 5.89 & $\mathrm{~d}(2.3)$ & 97.62 \\
\hline & 7 & & & 157.15 & & & 159.14 & & & 157.69 & & & 157.88 \\
\hline & 8 & 5.82 & $\mathrm{~d}(1.7)$ & 95.82 & 5.78 & $\mathrm{~d}(2.3)$ & 94.96 & 6.05 & $\mathrm{~s}$ & 96.00 & 6.02 & $\mathrm{~d}(2.3)$ & 96.12 \\
\hline \multirow[t]{6}{*}{ B } & 1 & & & 131.56 & & & 130.36 & & & 131.50 & & & 130.96 \\
\hline & 2 & 6.57 & $\mathrm{~s}$ & 107.94 & 6.50 & $\mathrm{~s}$ & 108.19 & 6.77 & $\mathrm{~s}$ & 107.23 & 6.74 & $\mathrm{~s}$ & 107.23 \\
\hline & 3 & & & 146.16 & & & 146.08 & & & 145.63 & & & 145.64 \\
\hline & 4 & & & 133.28 & & & 133.49 & & & 133.74 & & & 133.81 \\
\hline & 5 & & & 146.16 & & & 146.08 & & & 145.63 & & & 145.64 \\
\hline & 6 & 6.57 & $\mathrm{~s}$ & 107.94 & 6.50 & $\mathrm{~s}$ & 108.19 & 6.77 & $\mathrm{~s}$ & 107.23 & 6.74 & $\mathrm{~s}$ & 107.23 \\
\hline F & 2 & 5.31 & br s & 75.05 & & & & 5.31 & brs & 78.02 & 4.99 & $\mathrm{~d}(9.8)$ & 79.57 \\
\hline \multirow{3}{*}{ D } & 8 & & & 108.15 & & & & & & 106.13 & & & 105.98 \\
\hline & 9 & & & 154.34 & & & & & & 151.31 & & & 149.62 \\
\hline & 10 & & & 98.91 & & & & & & 104.48 & & & 104.33 \\
\hline \multirow[t]{6}{*}{$\mathrm{E}$} & 1 & & & 130.97 & & & & & & 130.62 & & & 129.08 \\
\hline & 2 & 6.67 & $\mathrm{~s}$ & 106.11 & & & & 6.56 & $\mathrm{~s}$ & 106.42 & 6.64 & $\mathrm{~s}$ & 108.00 \\
\hline & 3 & & & 145.94 & & & & & & 146.27 & & & 146.32 \\
\hline & 4 & & & 132.60 & & & & & & 133.08 & & & 134.05 \\
\hline & 5 & & & 145.94 & & & & & & 146.27 & & & 146.32 \\
\hline & 6 & 6.67 & $\mathrm{~s}$ & 106.11 & & & & 6.56 & $\mathrm{~s}$ & 106.42 & 6.64 & $\mathrm{~s}$ & 108.00 \\
\hline \multirow[t]{3}{*}{ I } & 2 & & & & & & & 5.29 & brs & 75.06 & & & \\
\hline & 3 & & & & & & & 4.14 & $\mathrm{~d}(2.3)$ & 71.18 & & & \\
\hline & 4 & & & & & & & 4.12 & $\mathrm{~d}(2.3)$ & 43.83 & & & \\
\hline
\end{tabular}


Table 1. Cont.

\begin{tabular}{|c|c|c|c|c|c|c|c|c|c|c|c|c|c|}
\hline \multirow{2}{*}{\multicolumn{2}{|c|}{ Position }} & \multicolumn{3}{|c|}{1} & \multicolumn{3}{|c|}{2} & \multicolumn{3}{|c|}{3} & \multicolumn{3}{|c|}{7} \\
\hline & & $\delta_{\mathrm{H}}$ & $(J$ in $\mathrm{Hz})$ & $\delta_{C}$ & $\delta_{\mathrm{H}}$ & $(J$ in $\mathrm{Hz})$ & $\delta_{C}$ & $\delta_{H}$ & $(J$ in $\mathrm{Hz})$ & $\delta_{C}$ & $\delta_{\mathrm{H}}$ & $(J$ in $\mathrm{Hz})$ & $\delta_{C}$ \\
\hline \multirow[t]{5}{*}{ G } & 5 & & & & & & & & & 156.77 & & & \\
\hline & 6 & & & & & & & 5.96 & $\mathrm{~s}$ & 97.45 & & & \\
\hline & 8 & & & & & & & & & 106.91 & & & \\
\hline & 9 & & & & & & & & & 153.90 & & & \\
\hline & 10 & & & & & & & & & 99.96 & & & \\
\hline \multirow[t]{4}{*}{$\mathrm{H}$} & 1 & & & & & & & & & 130.93 & & & \\
\hline & 4 & & & & & & & & & 132.74 & & & \\
\hline & 5 & & & & & & & & & 146.14 & & & \\
\hline & 6 & & & & & & & 6.70 & $\mathrm{~s}$ & 106.42 & & & \\
\hline \multicolumn{2}{|c|}{$\mathrm{CH}_{2} \mathrm{OH}-$} & $3.73-3.89$ & $\mathrm{~m}$ & 62.65 & $3.68-3.88$ & $\mathrm{~m}$ & 62.68 & $3.73-3.94$ & $\mathrm{~m}$ & 62.72 & $3.73-3.84$ & $\mathrm{~m}$ & 62.47 \\
\hline \multicolumn{2}{|c|}{$\mathrm{SCH}_{2-}^{-}$} & $2.75-2.96$ & $\mathrm{~m}$ & 34.95 & $2.75-3.11$ & $\mathrm{~m}$ & 37.22 & $2.78-2.99$ & $\mathrm{~m}$ & 35.14 & $2.77-3.09$ & $\mathrm{~m}$ & 37.54 \\
\hline
\end{tabular}

Table 2. ${ }^{1} \mathrm{H}-(500 \mathrm{MHz})$ and ${ }^{13} \mathrm{C}-(125 \mathrm{MHz}) \mathrm{NMR}$ data of 13 in methanol- $d_{4}, \mathbf{1 4}$ and 16 in acetone- $d_{6}$.

\begin{tabular}{|c|c|c|c|c|c|c|c|c|c|c|}
\hline \multirow{2}{*}{\multicolumn{2}{|c|}{ Position }} & \multicolumn{3}{|c|}{13} & \multicolumn{3}{|c|}{14} & \multicolumn{3}{|c|}{16} \\
\hline & & \multirow{2}{*}{$\begin{array}{c}\delta_{\mathbf{H}} \\
5.53\end{array}$} & \multirow{2}{*}{$\begin{array}{c}(J \text { in } \mathbf{H z}) \\
\text { br s }\end{array}$} & \multirow{2}{*}{$\frac{\delta_{C}}{70.22}$} & \multirow[t]{2}{*}{$\delta_{H}$} & \multirow[t]{2}{*}{$(J$ in $\mathrm{Hz})$} & \multirow{2}{*}{$\begin{array}{c}\delta_{\mathrm{C}} \\
99.97\end{array}$} & \multirow[t]{2}{*}{$\delta_{H}$} & \multirow[t]{2}{*}{$(J$ in $\mathrm{Hz})$} & \multirow{2}{*}{$\frac{\delta_{\mathbf{C}}}{100.21}$} \\
\hline C & 2 & & & & & & & & & \\
\hline & 3 & 4.05 & $\mathrm{dd}(2.4,1.0)$ & 74.27 & 4.22 & $\mathrm{~d}(3.5)$ & 67.26 & 4.15 & d (3.6) & 66.99 \\
\hline & 4 & 4.06 & br s & 45.70 & 4.38 & d (3.5) & 28.66 & 4.25 & d (3.6) & 28.74 \\
\hline \multirow[t]{6}{*}{ A } & 5 & & & 158.59 & & & 156.60 & & & 155.32 \\
\hline & 6 & 5.95 & $\mathrm{~d}(2.4)$ & 96.59 & 5.84 & $\mathrm{~d}(2.4)$ & 97.58 & 6.04 & $\mathrm{~d}(1.5)$ & 97.21 \\
\hline & 7 & & & 158.05 & & & 157.65 & & & 157.69 \\
\hline & 8 & 5.94 & $\mathrm{~d}(2.4)$ & 95.24 & 6.04 & $\mathrm{~d}(2.4)$ & 96.17 & 6.07 & br s & 96.21 \\
\hline & 9 & & & 157.76 & & & 153.79 & & & 153.96 \\
\hline & 10 & & & 102.49 & & & 104.06 & & & 104.26 \\
\hline \multirow[t]{6}{*}{ B } & 1 & & & 135.98 & & & 131.53 & & & 131.23 \\
\hline & 2 & 6.19 & $\mathrm{~s}$ & 108.50 & 6.78 & $\mathrm{~s}$ & 107.29 & 6.53 & $\mathrm{~s}$ & 107.32 \\
\hline & 3 & & & 146.47 & & & 145.62 & & & 145.62 \\
\hline & 4 & & & 132.19 & & & 133.73 & & & 133.76 \\
\hline & 5 & & & 146.47 & & & 145.62 & & & 145.62 \\
\hline & 6 & 6.19 & $\mathrm{~s}$ & 108.50 & 6.78 & $\mathrm{~s}$ & 107.29 & 6.53 & $\mathrm{~s}$ & 107.32 \\
\hline \multirow[t]{3}{*}{ F } & 2 & & & & 5.32 & br s & 78.12 & & & \\
\hline & 3 & & & & 3.95 & $\mathrm{~d}(2.3)$ & 72.61 & & & \\
\hline & 4 & & & & 4.63 & $\mathrm{~d}(2.3)$ & 36.24 & & & \\
\hline \multirow[t]{10}{*}{$\mathrm{D}$} & 1 & & & 104.59 & & & & & & 106.96 \\
\hline & 2 & & & 158.59 & & & & & & 153.81 \\
\hline & 3 & 5.79 & $\mathrm{~s}$ & 95.95 & & & & 5.96 & $\mathrm{~d}(1.5)$ & 96.01 \\
\hline & 4 & & & 159.52 & & & & & & 158.18 \\
\hline & 5 & 5.79 & $\mathrm{~s}$ & 95.95 & & & 156.16 & 6.03 & $\mathrm{~d}(1.5)$ & 97.19 \\
\hline & 6 & & & 158.59 & 6.02 & $\mathrm{~s}$ & 95.63 & & & 154.23 \\
\hline & 7 & & & & & & 151.54 & & & \\
\hline & 8 & & & & & & 105.79 & & & \\
\hline & 9 & & & & & & 157.65 & & & \\
\hline & 10 & & & & & & 104.58 & & & \\
\hline \multirow[t]{6}{*}{$\mathrm{E}$} & 1 & & & & & & 130.96 & & & \\
\hline & 2 & & & & 6.58 & $\mathrm{~s}$ & 106.42 & & & \\
\hline & 3 & & & & & & 146.27 & & & \\
\hline & 4 & & & & & & 133.02 & & & \\
\hline & 5 & & & & & & 146.27 & & & \\
\hline & 6 & & & & 6.58 & $\mathrm{~s}$ & 106.42 & & & \\
\hline \multirow[t]{6}{*}{ G } & 1 & & & & & & 106.90 & & & \\
\hline & 2 & & & & & & 151.31 & & & \\
\hline & 3 & & & & 6.05 & $\mathrm{~s}$ & 95.96 & & & \\
\hline & 4 & & & & & & 155.43 & & & \\
\hline & 5 & & & & 6.05 & $\mathrm{~s}$ & 95.96 & & & \\
\hline & 6 & & & & & & 151.31 & & & \\
\hline
\end{tabular}




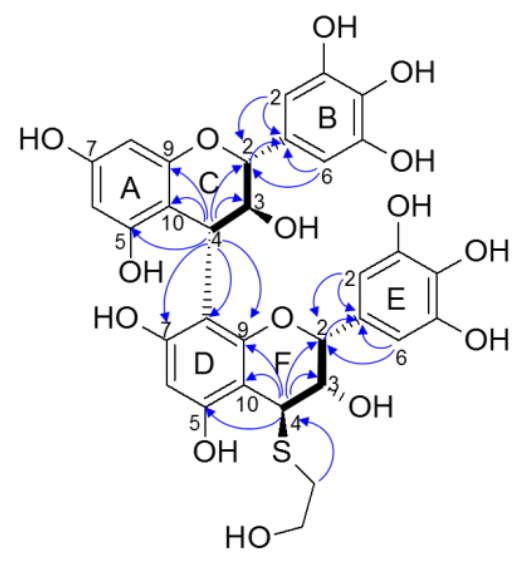

${ }^{1} \mathrm{H}-{ }^{1} \mathrm{H}$ COSY $-\mathrm{HMBC} \curvearrowright$

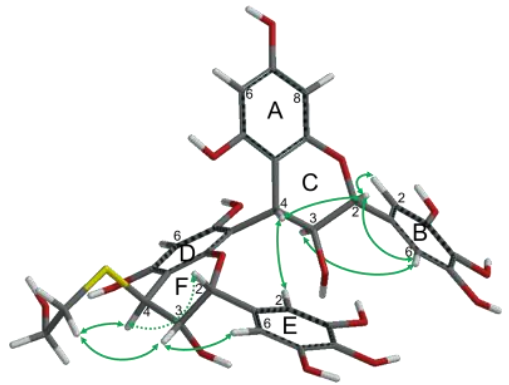

NOE $\sim($ strong $) \times--x($ weak $)$

Figure 6. HMBC, ${ }^{1} \mathrm{H}_{-}{ }^{1} \mathrm{H}$ COSY, and NOESY correlations of $\mathbf{1}$.

ECD spectroscopy allowed the determination of the absolute configuration at $\mathrm{C}-4$. The ${ }^{1} \mathrm{H}$ coupling constants of the $\mathrm{C}$-ring indicated that the B-ring was in an equatorial position ( $E$-conformer). Taking this observation into account, the negative Cotton effect at $218 \mathrm{~nm}$ implied an $\alpha$-orientation of the terminal unit at C-4 [40]. Thus, the extension unit was concluded to be (+)-gallocatechin. The establishment of the absolute configuration of the epigallocatechin unit relied on the Cotton effect at the ${ }^{1} \mathrm{~L}_{\mathrm{b}}$ band $(280 \mathrm{~nm})$ rather than the ${ }^{1} \mathrm{~L}_{\mathrm{a}}$ band $(220-240 \mathrm{~nm})$ [40]. Here, the negative Cotton effect at $288 \mathrm{~nm}$, in addition to the predominance of E-conformers, both led to the conclusion that the pyrogallol E-ring had an $\alpha$-orientation relative to the F-2 carbon. The terminal unit was thereby designated as (-)-epigallocatechin. Furthermore, the ECD spectrum for $\mathbf{1}$ showed a close resemblance to those of procyanidins B-4 previously observed by Barrett and colleagues [43]. Accordingly, $\mathbf{1}$ was concluded to be (+)-gallocatechin-(4 $\rightarrow 8)-(-)$-epigallocatechin-4-(2-hydroxyethyl)thioether.

Product 2 showed the $[\mathrm{M}+\mathrm{H}]^{+}$peak at $m / z 383.0801$ in HRFABMS, confirming the molecular formula as $\mathrm{C}_{17} \mathrm{H}_{18} \mathrm{O}_{8} \mathrm{~S}$. The ${ }^{1} \mathrm{H}-\mathrm{NMR}$ spectrum (Table 1) showed a doublet signal at $\delta_{\mathrm{H}} 4.77$ $(J=9.6 \mathrm{~Hz})$, indicating the 2,3-trans configuration characteristic of gallocatechin. The C-ring $\mathrm{H}-4$ resonated as a doublet at $\delta_{\mathrm{H}} 4.36(\mathrm{~J}=4.3 \mathrm{~Hz})$, which indicated the 3,4-cis configuration [31]. This was further confirmed by the appearance of a strong NOESY correlation between $\mathrm{H}-3$ and $\mathrm{H}-4$, and the absence of NOE between H-2 and H-4 (Figure 7). As for the absolute configuration, a negative Cotton effect at $284 \mathrm{~nm}$ in the ECD spectrum, which was similar to that of (+)-catechin [43], suggested $P$-helicity for the flavan A- and B-rings. Based on these results, 2 was concluded to be (+)-gallocatechin-4-(2-hydroxyethyl)thioether.

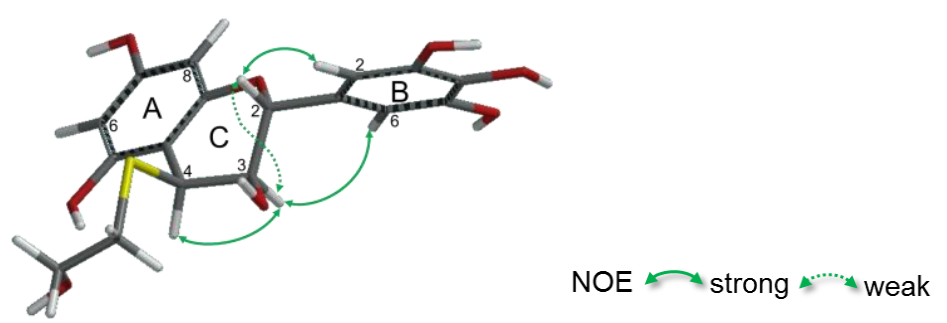

Figure 7. NOE correlations of 2.

Compound 3 was found to have the molecular formula $\mathrm{C}_{47} \mathrm{H}_{40} \mathrm{O}_{22} \mathrm{~S}$ based on the $[\mathrm{M}+\mathrm{Na}]^{+}$ peak at $m / z$ 1011.1639 in HRFABMS. This implied that 3 was a thioether of a prodelphinidin trimer involving both A-type and B-type linkages. In the ${ }^{1} \mathrm{H}-\mathrm{NMR}$ spectrum (Table 1), three intense aromatic singlets at $\delta_{\mathrm{H}} 6.77, \delta_{\mathrm{H}} 6.70$, and $\delta_{\mathrm{H}} 6.56$ (each $2 \mathrm{H}$ ) indicated the presence of three pyrogallol-type 
B-rings. The presence of two B-type linkages was apparent from the two C-ring H-2 signals resonating at $\delta_{\mathrm{H}} 5.31$ and $\delta_{\mathrm{H}} 5.29$ with small $J_{2,3}$ values $(<2 \mathrm{~Hz})$. This again indicated that the two units were epigallocatechin. These spectroscopic features suggested a close relationship between 3 and the epigallocatechin trimer isolated from E. sinica with A- and B-type linkages [12]. In the HMBC spectrum of 3 (Figure 8 ), the ketal carbon C-2 ( $\delta_{C}$ 99.91) of the A-type linkage was correlated to C-ring $\mathrm{H}-4$ $\left(\delta_{\mathrm{H}} 4.38, J=3.4 \mathrm{~Hz}\right)$, which was in turn correlated to a D-ring C-9 $\left(\delta_{\mathrm{C}} 151.31\right)$ of the middle unit. Another benzylic methine $\mathrm{H}-4$ of the middle unit F-ring $\left(\delta_{\mathrm{H}} 4.79, J=2.2 \mathrm{~Hz}\right)$ showed an HMBC correlation to the D-ring C-9 and terminal unit G-ring C-9 $\left(\delta_{C} 153.90\right)$. This indicated that an A-type linkage was involved between the top and middle units. The ${ }^{13} \mathrm{C}-\mathrm{NMR}$ chemical shift for F-ring C-4 at $\delta_{C} 36.21$ was consistent with its involvement in a B-type linkage at this position $[12,33,44]$, and the I-ring C-4 at a lower field $\left(\delta_{C} 43.83\right)$ was indicative of a thioether at this position [38]. The F-ring H-4 and I-ring H-4 were observed as doublet signals with coupling constants of $J=2.3 \mathrm{~Hz}$ and $J=2.4 \mathrm{~Hz}$, respectively, indicating that both flavan rings adopted a 3,4-trans configuration [31]. This was further supported by the absence of a NOESY correlation between H-2 and H-4 in both the F-ring and the I-ring (Figure 8). The linkage between rings $C$ and $D$ was established as $4 \rightarrow 8,2 \rightarrow O \rightarrow 7$ by the presence of a NOESY correlation between E-ring H-2,6 and C-ring H-4 [41]. The connection between the F-ring and the G-ring was also determined to be from C-4 to C-8 based on the NOESY cross peaks of H-ring H-2,6 with F-ring H-4 and H-3.
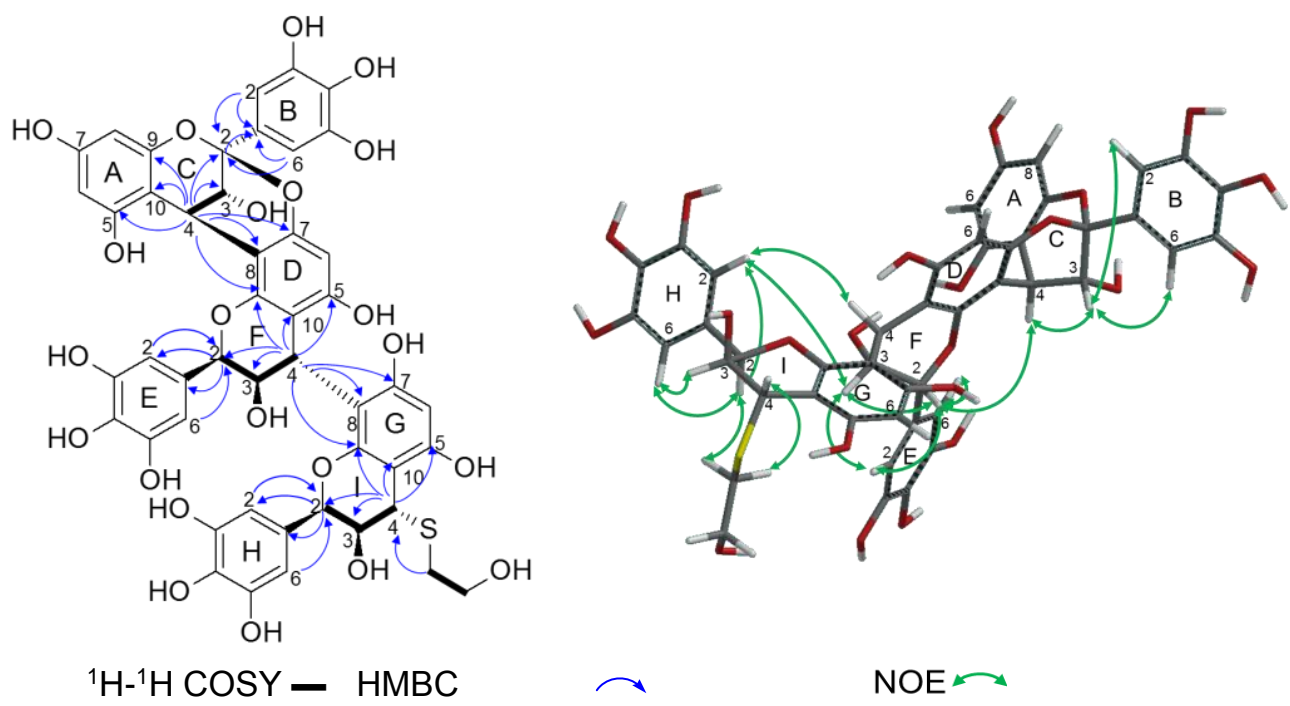

Figure 8. ${ }^{1} \mathrm{H}-{ }^{1} \mathrm{H}$ COSY and HMBC correlations (left) and NOESY correlations (right) of 3.

The ECD spectrum of 3 showed a strong positive Cotton effect at $233 \mathrm{~nm}$, reflecting the configuration at C-ring C-4, thereby establishing the top extension unit as (-)-epigallocatechin; however, the configuration of the middle and bottom epigallocatechin units could not be determined from the ECD data. Prodelphinidin oligomers with (+)-epigallocatechin units were previously isolated from the same plant source [12]; therefore, the absolute configuration of 3 was established by TDDFT calculations of the ECD spectra for four stereostructures: (a) (-)-epigallocatechin-(-)-epigallocatechin-(-)-epigallocatechin, (b) (-)-epigallocatechin-(+)-epigallocatechin-(-)-epigallocatechin, (c) (-)-epigallocatechin-(-)epigallocatechin-(+)-epigallocatechin, and (d) (-)-epigallocatechin-(+)-epigallocatechin(+)-epigallocatechin (Figure 9). The experimental ECD spectrum of 3 (Figure 9e) showed a positive Cotton effect at $233 \mathrm{~nm}$ and a negative Cotton effect at $218 \mathrm{~nm}$, similar to the Cotton effects observed in the calculated ECD spectra a and c. This comparison of calculated and experimental spectra revealed that the absolute structure of the upper and middle units in 3 was (-)-epigallocatechin. Moreover, the experimental spectrum e contained a weak negative Cotton effect at 250-300 nm, similar to the negative Cotton effect in the calculated ECD spectrum a. Therefore, 3 was established 
as (-)-epigallocatechin-( $4 \beta \rightarrow 8,2 \rightarrow O \rightarrow 7)-(-)$-epigallocatechin-( $4 \beta \rightarrow 8)-(-)$-epigallocatechin-4-(2hydroxyethyl)thioether.

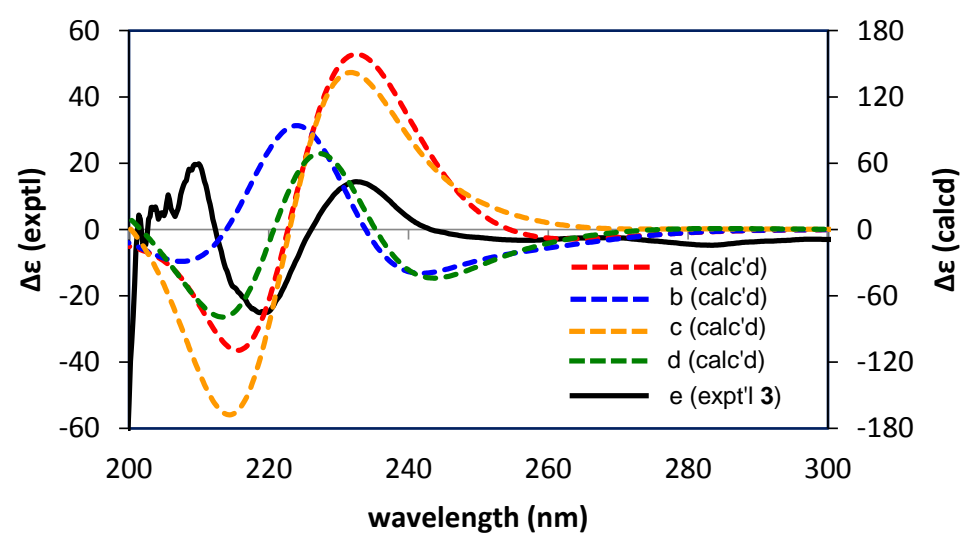

Figure 9. Calculated (a-d) and experimental (e) ECD spectra of prodelphinidin trimer thioether (3).

Compound 7 was characterized as an A-type prodelphinidin dimer with a mercaptoethanol substituent, and its molecular formula was determined as $\mathrm{C}_{32} \mathrm{H}_{28} \mathrm{O}_{15} \mathrm{~S}$ from the $[\mathrm{M}+\mathrm{Na}]^{+}$peak at $\mathrm{m} / \mathrm{z}$ 707.1043 in HRFABMS. The presence of an A-type linkage was apparent from the signal at $\delta_{C} 100.07$, attributable to the C-ring C-2 ketal carbon [12,42]. The large coupling constant $(J=9.8 \mathrm{~Hz})$ of the $\mathrm{H}-2$ at $\delta_{\mathrm{H}} 4.99$ indicated the 2,3-trans configuration of the lower unit F-ring. The coupling constants of the C-ring H-4 at $\delta_{\mathrm{H}} 4.17(\mathrm{~J}=3.6 \mathrm{~Hz})$ and F-ring $\mathrm{H}-4$ at $\delta_{\mathrm{H}} 4.39(\mathrm{~J}=4.3 \mathrm{~Hz})$, which were similar to the values observed in 2, suggested the 3,4-cis configuration of these rings. A comparison of the ${ }^{1} \mathrm{H}$ - and ${ }^{13} \mathrm{C}-\mathrm{NMR}$ data with those in the literature suggested that the dimer was composed of epigallocatechin and gallocatechin [12,37]. This was supported by a strong NOE between F-3 and F-4, and weak NOE between F-2 and F-3 (Figure 10). The linkage between the C- and D-rings was established to be $4 \rightarrow 8$ by the observation of a NOESY correlation between C-ring $\mathrm{H}-4$ and E-ring H-2,6. The absolute configuration at the C-ring C-4 was established by ECD spectroscopy, where the strong negative Cotton effect at $228 \mathrm{~nm}$ indicated that the extension unit was (+)-epigallocatechin. The terminal unit was designated as (+)-gallocatechin based on a comparison of the ECD spectrum with that of compound 2, which also had a negative Cotton effect, of a lesser amplitude, at $284 \mathrm{~nm}$. Compound 7 was thereby established as (-)-epigallocatechin-( $4 \alpha \rightarrow 8,2 \rightarrow O \rightarrow 7)-(+)$-gallocatechin-4-(2-hydroxyethyl)thioether.

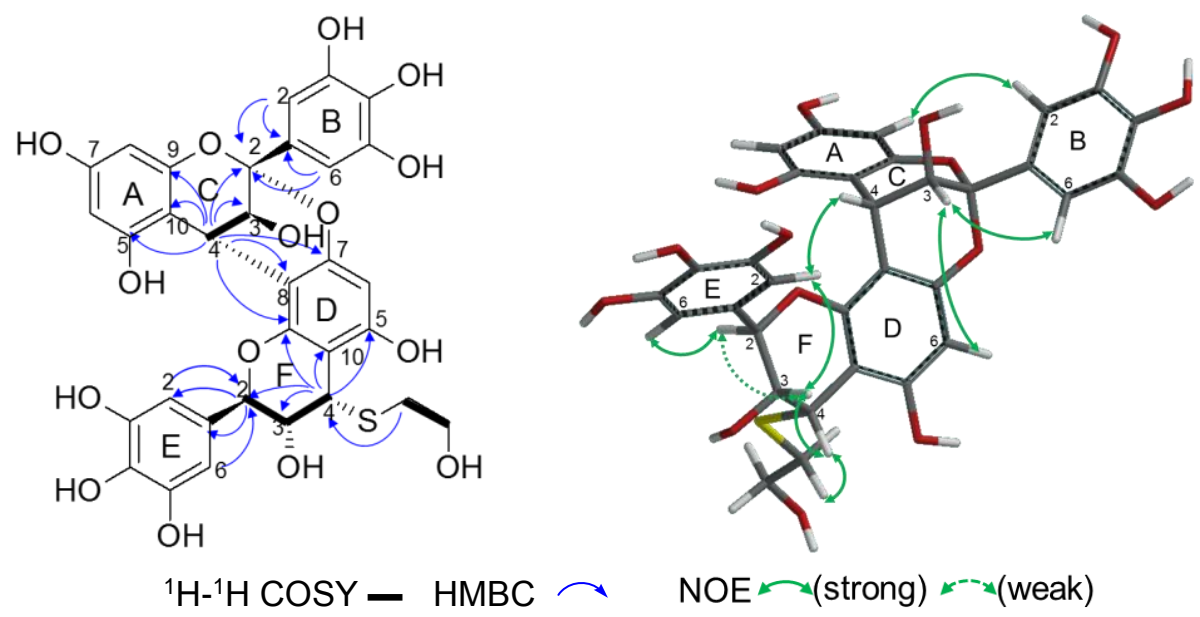

Figure 10. ${ }^{1} \mathrm{H}_{-}{ }^{1} \mathrm{H}$ COSY, HMBC, and NOESY correlations of 7. 
Compound 13 was obtained as a product of phloroglucinolysis, and the HRFABMS peak $\left(\mathrm{m} / z 431.0979[\mathrm{M}+\mathrm{H}]^{+}\right)$confirmed the molecular formula as $\mathrm{C}_{21} \mathrm{H}_{18} \mathrm{O}_{10}$, the same as that of $\mathbf{1 1}$ and $\mathbf{1 2}$. Because of overlapping C-ring proton signals in the ${ }^{1} \mathrm{H}-\mathrm{NMR}$ spectrum measured in acetone- $d_{6}$, the 2D NMR spectra were measured in methanol- $d_{4}$ (Table 2). The resulting ${ }^{1} \mathrm{H}-\mathrm{NMR}$ spectrum showed signals attributable to pyrogallol $\left(\delta_{\mathrm{H}} 6.19,2 \mathrm{H}\right)$ and phloroglucinol $\left(\delta_{\mathrm{H}} 5.79,2 \mathrm{H}\right)$ rings, as well as mutually meta-coupled A-ring H-6 and $\mathrm{H}-8\left(\delta_{\mathrm{H}} 5.94\right.$ and $\left.5.95, J=2.4 \mathrm{~Hz}\right)$, which were related to those observed in the spectra of $\mathbf{1 1}$ and $\mathbf{1 2}$ [12,37,42]. In the ${ }^{1} \mathrm{H}^{-1} \mathrm{H}$ COSY spectrum (Figure 11), a broad aliphatic singlet signal at $\delta_{\mathrm{H}} 5.53$ was correlated to a methine signal at $\delta_{\mathrm{H}} 4.05(\mathrm{~J}=2.4,1.0 \mathrm{~Hz})$, and these signals were attributed to $\mathrm{C}$-ring $\mathrm{H}-2$ and $\mathrm{H}-3$, respectively. The small coupling constant suggested the 2,3-cis configuration [33]. Another aliphatic methine signal at $\delta_{\mathrm{H}} 4.06$ was assigned to C-ring H-4 based on its HMBC correlations to A-ring C-5, 9 and 10 (Figure 11). H-4 also showed HMBC correlations with pyrogallol $\mathrm{H}-2,6\left(\delta_{\mathrm{H}} 6.19\right)$, indicating that the pyrogallol ring was attached to $\mathrm{C}-4$. This was further supported by the long-range ${ }^{1} \mathrm{H}-{ }^{1} \mathrm{H}$ coupling between $\mathrm{C}$-ring $\mathrm{H}-4$ and pyrogallol B-ring $\mathrm{H}-2,6$ in the ${ }^{1} \mathrm{H}^{-1} \mathrm{H}$ COSY spectrum and the HMBC cross peak between C-ring $\mathrm{H}-3$ and pyrogallol C-1 [45]. The remaining moiety, i.e., the phloroglucinol ring with a symmetrical structure, was shown to be located at C-ring C-2 by the HMBC correlation of C-ring H-2 to the phloroglucinol C-1, 2, and 6. The 2,3-cis-3,4-trans configuration was inferred by a comparison of the coupling constants with those in the literature [31], and this was further supported by the absence of NOE between H-2 and H-4 and occurrence of the strong NOE between C-ring H-2 and pyrogallol B-ring H-2,6 (Figure 11). The weak correlation observed between the $\mathrm{C}$-ring $\mathrm{H}-2$ and A-ring $\mathrm{H}-8$ protons suggested that $\mathrm{H}-2$ was at the axial position, thereby implying that the $\mathrm{C}$-ring adopted the $E$-conformation. From the positive Cotton effect at $227 \mathrm{~nm}$, the absolute configuration at C-4 was determined to be $S$ [31]. Accordingly, 13 was concluded to be 2-(2,4,6-trihydroxyphenyl)-4-(3,4,5-trihydroxyphenyl)-3,4-dihydro-2H-1-benzopyran-3,5,7-triol $(2 R, 3 R, 4 S)$. This compound was a byproduct of phloroglucinolysis, and a plausible production mechanism is proposed in Scheme 2.
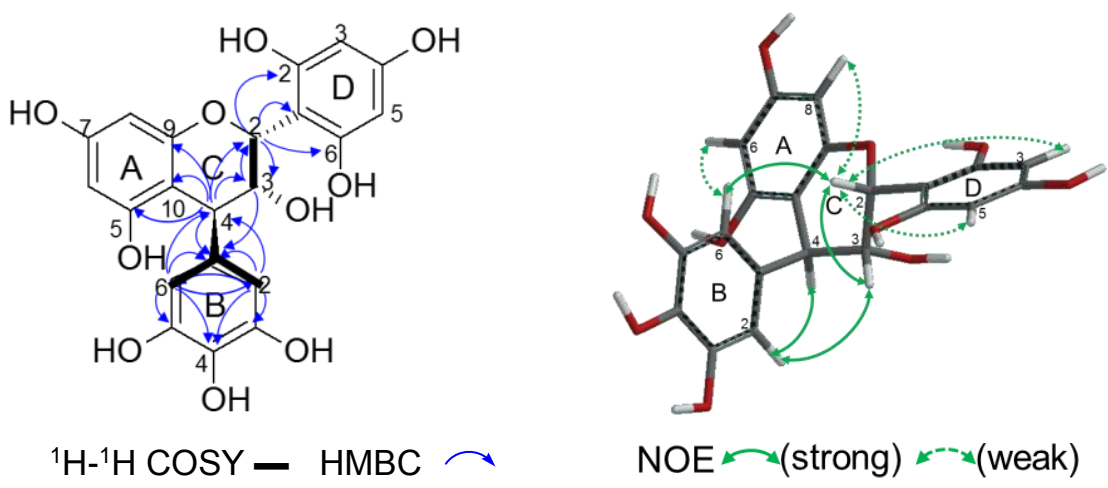

Figure 11. ${ }^{1} \mathrm{H}-{ }^{-1} \mathrm{H}$ COSY, HMBC, and NOESY correlations of $\mathbf{1 3 .}$
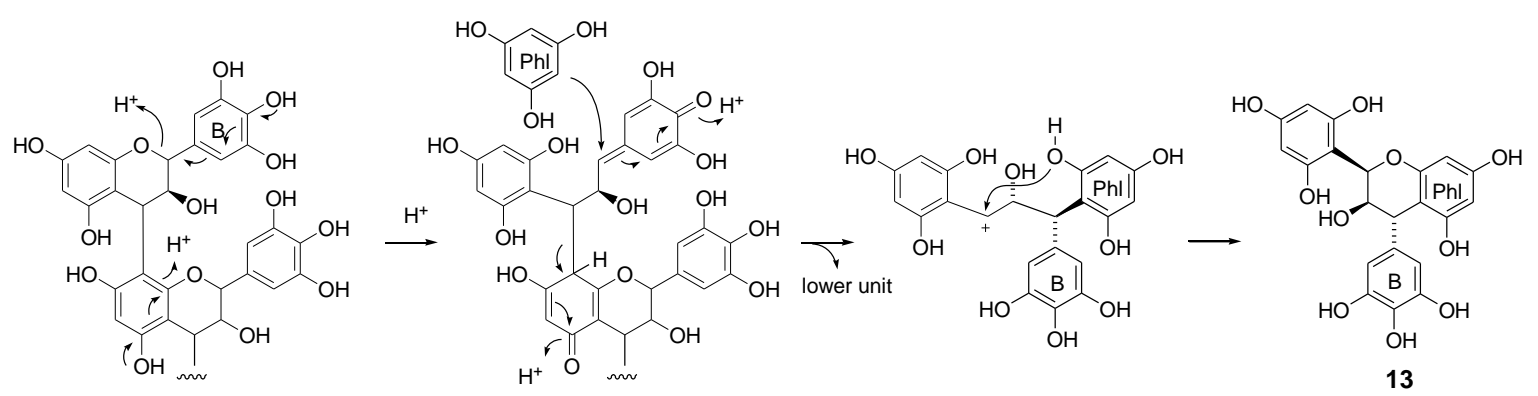

Scheme 2. A possible production mechanism of 13. 
Compound 14 was determined to have the molecular formula $\mathrm{C}_{36} \mathrm{H}_{28} \mathrm{O}_{17}(\mathrm{~m} / z$ 733.1406, $[\mathrm{M}+\mathrm{H}]^{+}$), identifying it as a phloroglucinol adduct of a prodelphinidin dimer involving an A-type linkage. The signals in the ${ }^{1} \mathrm{H}$ - and ${ }^{13} \mathrm{C}-\mathrm{NMR}$ spectra were related to those of the epigallocatechin-epigallocatechin dimer [12] and the procyanidin A2-phloroglucinol adduct [46], and their assignments (Table 2) were based on a comparison with the reported data. The signal of F-ring $\mathrm{H}-2\left(\delta_{\mathrm{H}} 5.32\right)$ was observed as a singlet, indicating the 2,3-cis configuration of the F-ring [33]. In addition, the coupling constant of the F-ring H-4 $\left(\delta_{\mathrm{H}} 4.63, J=2.3 \mathrm{~Hz}\right)$ was consistent with the 3,4-trans configuration [31]. This was confirmed by the NOESY spectrum, which displayed a strong correlation between F-ring H-3 and H-4, but no NOE between H-2 and H-4 (Figure 12). The $4 \rightarrow 8$ linkage between the C- and D-rings was established by the NOE between E-ring H-2,6 and C-ring $\mathrm{H}-4$. Furthermore, the strong positive Cotton effect at $232 \mathrm{~nm}$ established that the upper unit was (-)-epigallocatechin [12]. On the basis of previous studies of compound 7, by Nam et al. [42] and Barrett et al. [43], and considering the weak positive Cotton effect at 220-240 nm of 12, the lower unit was deduced to be (-)-epigallocatechin. It was therefore concluded that compound $\mathbf{1 4}$ was (-)-epigallocatechin- $(4 \beta \rightarrow 8,2 \rightarrow O \rightarrow 7)-(-)$-epigallocatechin-4-phloroglucinol.
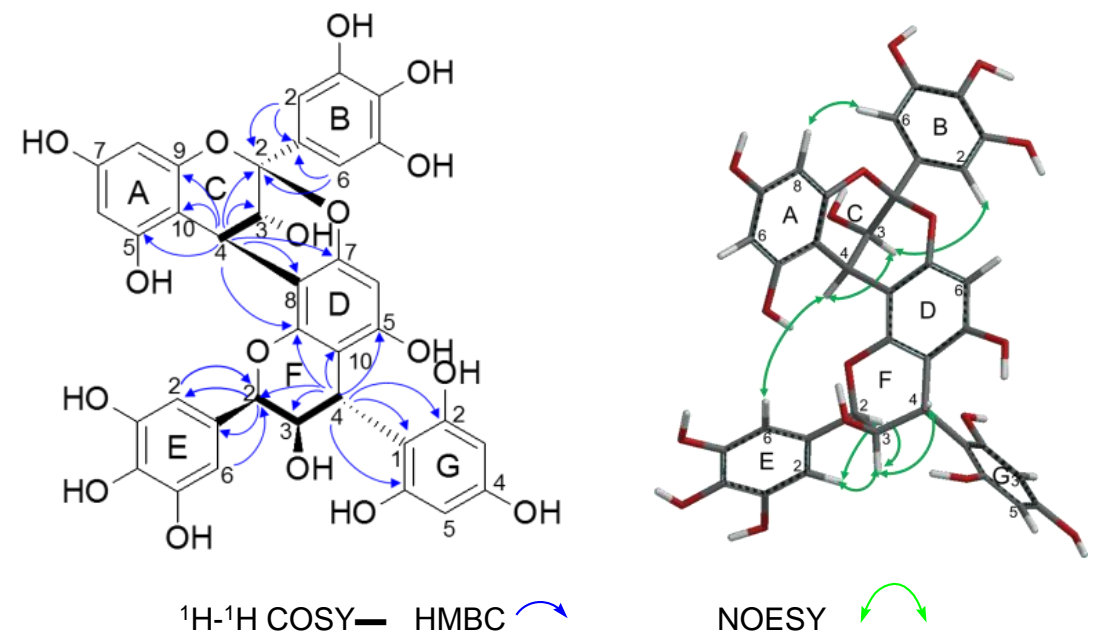

Figure 12. ${ }^{1} \mathrm{H}_{-}{ }^{1} \mathrm{H}$ COSY, HMBC, and NOESY correlations of 14.

Product 16 showed the $[\mathrm{M}+\mathrm{H}]^{+}$peak at $m / z 429.0818$ in HRFABMS, indicating the molecular formula $\mathrm{C}_{21} \mathrm{H}_{16} \mathrm{O}_{10}$. An unambiguous assignment of the ${ }^{1} \mathrm{H}$ - and ${ }^{13} \mathrm{C}-\mathrm{NMR}$ signals was achieved by ${ }^{1} \mathrm{H}-{ }^{1} \mathrm{H}$ COSY, HSQC, HMBC, and NOESY spectroscopy. The absence of a C-2 proton signal and appearance of a C-2 carbon signal at $\delta_{C} 100.21$ confirmed the presence of an A-type linkage [12,44,46]. The HMBC cross peaks (Figure 13) between C-ring H-4 and D-ring C-1,2,6 indicated the linkage of the phloroglucinol moiety to C-ring C-4. The NOE cross peaks between H-3 and B-ring H-2,6 indicated the 3,4-trans configuration [47]. Furthermore, the ECD spectrum showed a positive Cotton effect at $220-240 \mathrm{~nm}$, indicating a $\beta$ - configuration at C-4. Accordingly, 16 was established to be (-)-epigallocatechin-( $4 \beta \rightarrow 1,2 \rightarrow O \rightarrow 2)$-phloroglucinol. Compound 16 was regarded as a byproduct of phloroglucinolysis involving the oxidation of the pyrogallol-type B-ring (Scheme 3) [45]. 


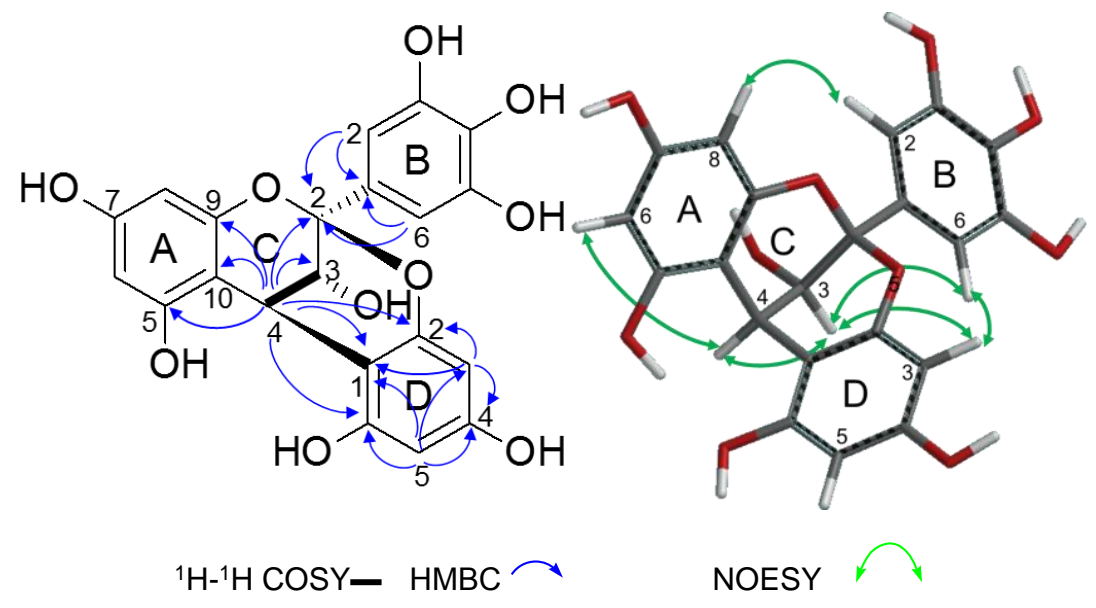

Figure 13. ${ }^{1} \mathrm{H}-{ }^{1} \mathrm{H}$ COSY, HMBC, and NOESY correlations of $\mathbf{1 6}$.

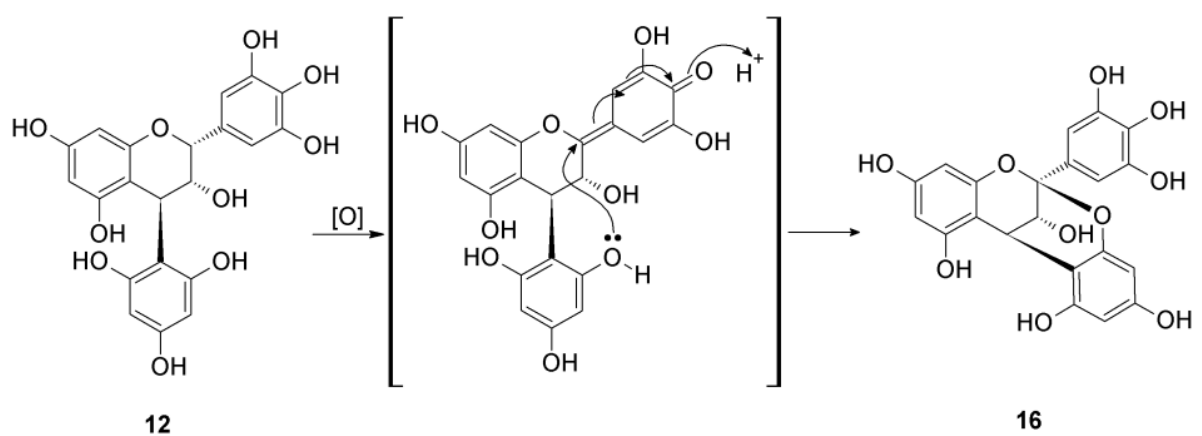

Scheme 3. Formation of $\mathbf{1 6}$ by oxidative hydride abstraction.

\section{Materials and Methods}

\subsection{General}

NMR spectra were recorded in acetone- $d_{6}$ (Wako Pure Chem. Ind. Ltd., Osaka, Japan), methanol- $d_{4}$ (Kanto Chem. Co., Inc., Tokyo, Japan), and DMSO- $d_{6}$ (Kanto Chemical Co., Inc., Tokyo, Japan) with a Varian Unity Plus 500 spectrometer (Palo Alto, CA, USA) operating at $500 \mathrm{MHz}$ for ${ }^{1} \mathrm{H}$ and $125 \mathrm{MHz}$ for ${ }^{13} \mathrm{C}$, and with a JEOL JNM-AL 400 spectrometer (JEOL Ltd, Tokyo, Japan) at $400 \mathrm{MHz}$ for ${ }^{1} \mathrm{H}$ and $100 \mathrm{MHz}$ for ${ }^{13} \mathrm{C}$. HRFABMS spectra were recorded on a JMS $700 \mathrm{~N}$ spectrometer (JEOL Ltd., Tokyo, Japan) in positive ion mode, with glycerol or $m$-nitrobenzyl alcohol, with or without $\mathrm{NaCl}$, as the matrix. UV spectra were recorded in $\mathrm{MeOH}$ with a Jasco V-560 UV/Vis spectrometer (Jasco Co. Ltd., Tokyo, Japan). The same solvent was used for the ECD spectroscopic analysis using a Jasco-725N spectrometer (Jasco Co. Ltd., Tokyo, Japan), and optical rotation measurement using a Jasco P-1020 (Jasco Co. Ltd., Tokyo, Japan). IR spectra were recorded using a Jasco FT/IR-410K (Jasco Co. Ltd., Tokyo, Japan). Column chromatography was performed using a Sephadex LH-20 (25-100 mm, GE Healthcare UK Ltd., Buckinghamshire HP7 9NA, UK), a Diaion HP20SS (Mitsubishi Chemical Co., Tokyo, Japan), and a Chromatorex ODS (Fuji Silysia Chemical Ltd., Kasugai, Japan). TLC was performed on 0.25-mm thick, precoated silica gel $60 \mathrm{~F}_{254}$ (Merck, Darmstadt, Germany) with toluene-ethyl formate-formic acid $(1: 7: 1, v / v)$ as the solvent system. Spots were detected by illumination under a short wavelength UV $(254 \mathrm{~nm})$ followed by spraying with $2 \%$ ethanolic $\mathrm{FeCl}_{3}$. Analytical HPLC was performed with gradient elution from 4-30\% (39 $\mathrm{min}), 30-75 \%$ (15 min), 75-95\% (6 min) acetonitrile (Kanto Chemical Co., Inc., Tokyo, Japan) in $50 \mathrm{mM}$ phosphoric acid (Kishida Chemical Co., Osaka, Japan) on a Cosmosil 5C 18 -ARII $4.6 \times 250 \mathrm{~mm}$ column (Nacalai Tesque, Inc., Kyoto, Japan) at a flow rate of $0.8 \mathrm{~mL} / \mathrm{min}$, using an HPLC system composed of a Jasco DG-2080-53 
Plus degasser, Jasco PU-2080 Plus pump, Jasco AS-2055 Plus autosampler, Jasco CO-2065 Plus column oven (maintained at $35^{\circ} \mathrm{C}$ ), and Jasco MD-2018 Plus PDA detector (Jasco Co. Ltd., Tokyo, Japan).

\subsection{Plant Material}

Dried aerial parts of Ephedra sinica were purchased from Uchida Wakanyaku Ltd., Tokyo, Japan.

\subsection{Extraction and Isolation}

The dried aerial parts (500 g) of E. sinica were extracted with 70\% acetone $(3 \mathrm{~L})$ at room temperature overnight, three times. The extracts were combined and concentrated by rotary evaporation under reduced pressure at $40{ }^{\circ} \mathrm{C}$. The resulting aqueous solution was charged into a Sephadex LH-20 $(5 \mathrm{~cm} \times 19 \mathrm{~cm})$ and eluted with $\mathrm{H}_{2} \mathrm{O}-\mathrm{MeOH}(0-100 \%, 20 \%$ stepwise gradient) and $60 \%$ acetone to give two fractions: Fr. 1 and 2 (Figure S1). The first fraction eluted with $\mathrm{H}_{2} \mathrm{O}$ was acidified with trifluoroacetic acid and loaded into a Diaion HP20SS column $(5 \mathrm{~cm} \times 30 \mathrm{~cm})$. After washing out sugars and inorganic substances with $\mathrm{H}_{2} \mathrm{O}$, the column was eluted with $0-100 \% \mathrm{MeOH}(10 \%$ stepwise gradient) and then $60 \%$ acetone to give Fr. 1-1 (9.16 g) containing proanthocyanidin oligomers and Fr. 1-2 (14.57 g) containing oligomers and low-molecular weight proanthocyanidins. A portion ( $5 \mathrm{~g}$ ) of Fr. 1-2 was separated by size-exclusion column chromatography using a Sephadex LH-20 $(4 \mathrm{~cm} \times 45 \mathrm{~cm})$ with a mixture of acetone and $7 \mathrm{M}$ urea $(3: 2, v / v$, containing conc. $\mathrm{HCl} 5 \mathrm{~mL} / \mathrm{L})$ to afford Fr. 1-2-1 containing oligomers and Fr. 1-2-2 containing low-molecular weight polyphenols. After the removal of acetone by evaporation, the resulting aqueous solution of Fr. 1-2-1 was subjected to Diaion HP20SS $(3 \mathrm{~cm} \times 19 \mathrm{~cm})$ column chromatography, and urea and $\mathrm{HCl}$ were washed out by elution with $\mathrm{H}_{2} \mathrm{O}$. Subsequent elution of the column with $0-100 \% \mathrm{MeOH}$ (10\% stepwise gradient) yielded Fr. 1-2-1-1 (1.11 g) containing oligomeric proanthocyanidins. Separately, Fr. 2 was subjected to size-exclusion chromatography in a manner similar to that described for Fr. 1-2 to give three fractions. The resulting Fr. 2-2 was loaded into a Diaion HP20SS column to remove urea and $\mathrm{HCl}$, yielding oligomeric proanthocyanidins (Fr. 2-2-2, $3.36 \mathrm{~g}$ ).

\subsection{Thiolysis}

Thiol degradation was performed according to the method of Kusano et al. [35] with modifications. Proanthocyanidin oligomers (Fr. 1-1, 1.0 g) were dissolved in $60 \% \mathrm{EtOH}$ (200 mL) containing mercaptoethanol (10 mL) (Kanto Chemical Co. Inc., Tokyo, Japan) and concentrated $\mathrm{HCl}(0.5 \mathrm{~mL})$ (Kishida Chemical Co., Osaka, Japan). The reaction mixture was then heated at $70{ }^{\circ} \mathrm{C}$ for $22 \mathrm{~h}$. The reaction mixture was then analyzed by HPLC and was further fractionated. Fr. 2-2-2 (1.0 g) was also subjected to thiolysis in the same manner. The reaction mixture of Fr. 1-1 was first concentrated to remove EtOH. The resulting aqueous solution was subjected to Sephadex LH-20 chromatography $(3 \mathrm{~cm} \times 24 \mathrm{~cm})$, and mercaptoethanol was washed out with $\mathrm{H}_{2} \mathrm{O}$. Further elution of the column with increasing proportions of $\mathrm{MeOH}$ in $\mathrm{H}_{2} \mathrm{O}(0-50 \%, 5 \%$ stepwise gradient; $50-100 \%, 10 \%$ stepwise gradient) gave eight fractions. Fr 1-1-5 $(0.35 \mathrm{~g})$ was loaded into a Diaion HP20SS $(3 \mathrm{~cm} \times 22 \mathrm{~cm})$ with $\mathrm{H}_{2} \mathrm{O}-\mathrm{MeOH}$ to furnish five subfractions. Purification of Fr. 1-1-5-4 (41.9 mg) by Sephadex LH-20 chromatography $(3 \mathrm{~cm} \times 25 \mathrm{~cm})$ with a systematic stepwise gradient of $\mathrm{EtOH}-\mathrm{H}_{2} \mathrm{O}$-acetone (1:0:0, 9:1:0, 8:2:0, 6:4:0, 54:36:10, 48:32:20, 36:24:40, 0:50:50, $v / v)$ enabled the isolation of $\mathbf{1 0}(19.5 \mathrm{mg})$. Separation of Fr. 1-1-5-3 (178.7 mg) with the same chromatographic procedure afforded compounds $4(4.9 \mathrm{mg})$ and 6 (60.8 mg). Fr. 1-1-5-2 (72.9 mg) was separated by Chromatorex ODS chromatography $(3 \mathrm{~cm} \times 17 \mathrm{~cm})$ with $\mathrm{H}_{2} \mathrm{O}-\mathrm{MeOH}$ and a Sephadex LH-20 $(2.5 \mathrm{~cm} \times 13 \mathrm{~cm})$ with $\mathrm{H}_{2} \mathrm{O}-\mathrm{MeOH}$ to afford $6(21.0 \mathrm{mg})$, $1(5.2 \mathrm{mg})$, and $2(21.3 \mathrm{mg})$. Separation of Fr. 1-1-7 by Diaion HP20SS chromatography $(2 \times 17 \mathrm{~cm})$ with $\mathrm{H}_{2} \mathrm{O}-\mathrm{MeOH}$ afforded six subfractions, and Fr. 1-1-7-3 (104.3 $\mathrm{mg}$ ) was further separated by Chromatorex ODS chromatography $(2 \mathrm{~cm} \times 16 \mathrm{~cm})$ with $\mathrm{H}_{2} \mathrm{O}-\mathrm{MeOH}$ to give $3(21.2 \mathrm{mg}), 7(19.3 \mathrm{mg})$, and $9(9.0 \mathrm{mg})$. The thiol degradation products of the other oligomers, Fr. 2-2-2, were also fractionated in the same manner as described for Fr. 1-1 to give seven subfractions. Fr. 2-2-2-6 (241.5 mg) was separated by Diaion HP20SS column chromatography $(3 \mathrm{~cm} \times 16 \mathrm{~cm})$ with $\mathrm{H}_{2} \mathrm{O}-\mathrm{MeOH}(0-100 \%$, 
$20 \%$ stepwise gradient). Among the six subfractions obtained, the separation of Fr. 2-2-2-6-3 (74.5 mg) by a Chromatorex ODS $(2.5 \mathrm{~cm} \times 15 \mathrm{~cm})$ with $\mathrm{H}_{2} \mathrm{O}-\mathrm{MeOH}$ yielded $5(0.6 \mathrm{mg}), 7(36.2 \mathrm{mg})$, and $9(10.0 \mathrm{mg})$. The same chromatographic procedure using a Chromatorex ODS was applied to the separation of Fr. 2-2-2-6-4 (49.3 mg), which yielded $\mathbf{9}(21.0 \mathrm{mg})$ and a crude crop of 8 . The latter was purified by Sephadex LH-20 $(2 \mathrm{~cm} \times 16 \mathrm{~cm})$ and a system of increasing $\mathrm{MeOH}$ concentration in $\mathrm{H}_{2} \mathrm{O}$ (0-40\%, 20\% stepwise gradient; $40-100 \%, 5 \%$ stepwise gradient), which led to the isolation of 8 (8.8 mg).

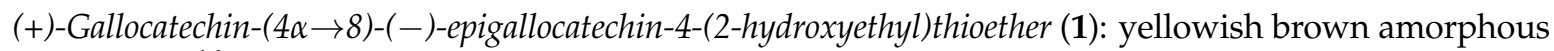
powder; $[\alpha]_{\mathrm{D}}^{16}-105.9(c=0.10, \mathrm{MeOH}) ; \mathrm{UV}(\mathrm{MeOH}) \lambda_{\max }(\log \varepsilon) 270$ (3.61), 239 (4.41), 214 (5.00) nm; $\mathrm{CD}(\mathrm{MeOH}) \Delta \varepsilon_{218}-33.1, \Delta \varepsilon_{288}-2.3$; IR $v_{\max } 3311,1609,1449,1541,1449 \mathrm{~cm}^{-1}$; HRFABMS $\mathrm{m} / \mathrm{z}$ $687.1382[\mathrm{M}+\mathrm{H}]^{+}$(calcd for $\left.\mathrm{C}_{32} \mathrm{H}_{31} \mathrm{O}_{15} \mathrm{~S}, 687.1378\right) ;{ }^{1} \mathrm{H}$ - and ${ }^{13} \mathrm{C}-\mathrm{NMR}$ data, see Table 1 .

(+)-Gallocatechin-4-(2-hydroxyethyl)thioether (2): pale brown amorphous powder; $[\alpha]_{\mathrm{D}}^{16}+29.9(c=0.13$, $\mathrm{MeOH}) ; \mathrm{UV}(\mathrm{MeOH}) \lambda_{\max }(\log \varepsilon) 273$ (3.17), 235 (4.42), 209 (4.72) nm; CD (MeOH) $\Delta \varepsilon_{220}-2.8$, $\Delta \varepsilon_{249}+2.2, \Delta \varepsilon_{284}-0.4 ;$ IR $v_{\max } 3344,1621,1537,1515,1455,1345 \mathrm{~cm}^{-1}$; HRFABMS $\mathrm{m} / z 383.0801$ $[\mathrm{M}+\mathrm{H}]^{+}$(calcd for $\left.\mathrm{C}_{17} \mathrm{H}_{19} \mathrm{O}_{8} \mathrm{~S}, 383.0795\right) ;{ }^{1} \mathrm{H}$ - and ${ }^{13} \mathrm{C}-\mathrm{NMR}$ data, see Table 1 .

(-)-Epigallocatechin- $(4 \beta \rightarrow 8,2 \rightarrow O \rightarrow 7)-(-)$-epigallocatechin- $(4 \alpha \rightarrow 8)-(-)$-epigallocatechin-4-(2-hydroxyethyl) thioether (3): reddish brown amorphous powder; $[\alpha]_{\mathrm{D}}^{20}-17.2(c=0.11, \mathrm{MeOH}) ; \mathrm{UV}(\mathrm{MeOH}) \lambda_{\max }(\log \varepsilon)$ 270 (3.83), 241 (4.65), 205 (5.31) nm; CD (MeOH) $\Delta \varepsilon_{218}-25.0, \Delta \varepsilon_{233}+14.2, \Delta \varepsilon_{284}-4.3$; IR $v_{\max } 3276$, $1615,1541,1445,1348 \mathrm{~cm}^{-1}$; HRFABMS $m / z 1011.1639$ [M + Na] ${ }^{+}$(calcd for $\mathrm{C}_{47} \mathrm{H}_{40} \mathrm{O}_{22} \mathrm{SNa}, 1011.1624$ ); ${ }^{1} \mathrm{H}$ - and ${ }^{13} \mathrm{C}-\mathrm{NMR}$ data, see Table 1.

(+)-Epigallocatechin-( $4 \alpha \rightarrow 8,2 \alpha \rightarrow O \rightarrow 7)-(+)-$ gallocatechin-4-(2-hydroxyethyl)thioether (7): pale brown amorphous powder; $[\alpha]_{\mathrm{D}}^{17}-50.1(c=0.15, \mathrm{MeOH}) ; \mathrm{UV}(\mathrm{MeOH}) \lambda_{\max }(\log \varepsilon) 270$ (3.55), 247 (4.32), 208 (5.00) nm; $\mathrm{CD}(\mathrm{MeOH}) \Delta \varepsilon_{228}-25.6, \Delta \varepsilon_{252}+3.7, \Delta \varepsilon_{284}-3.0$; IR $v_{\max } 3389,1612,1537,1502,1447,1333 \mathrm{~cm}^{-1}$; HRFABMS $m / z 707.1043[\mathrm{M}+\mathrm{Na}]^{+}$(calcd for $\mathrm{C}_{32} \mathrm{H}_{28} \mathrm{O}_{15} \mathrm{SNa}, 707.1041$ ); ${ }^{1} \mathrm{H}-$ and ${ }^{13} \mathrm{C}-\mathrm{NMR}$ data, see Table 1.

\subsection{Phloroglucinolysis}

Fr. 1-1 was subjected to phloroglucinolysis according to the method reported by Kennedy and Jones and Bautista-Ortin and colleagues [18,36], with a few modifications. Fr. 1-1 (2.0 g) was dissolved in $\mathrm{MeOH}(200 \mathrm{~mL})$ and then mixed with phloroglucinol reagent $(200 \mathrm{~mL})$. This phloroglucinol reagent was a methanolic solution containing phloroglucinol (20 g) (Sigma Chemical Co., St. Louis, MO, USA), ascorbic acid (4 g) (Kishida Chemical Co., Osaka, Japan), and concentrated $\mathrm{HCl}(2.92 \mathrm{~mL}$ ). The mixture was heated at $50{ }^{\circ} \mathrm{C}$ for $60 \mathrm{~min}$, and the reaction was then terminated by the addition of $0.2 \mathrm{M}$ sodium acetate $(800 \mathrm{~mL})$. The reaction mixture was concentrated in vacuo to remove $\mathrm{MeOH}$ and acidified to $\mathrm{pH} 4$ prior to fractionation. The aqueous solution was loaded into a Sephadex LH-20 column $\left(3 \mathrm{~cm} \times 24 \mathrm{~cm}\right.$ ) and eluted with $\mathrm{H}_{2} \mathrm{O}$ containing increasing proportions of $\mathrm{MeOH}$ to give 10 fractions. Fr. 1-1-5 $(810.7 \mathrm{mg})$ was separated by Diaion HP $20 \mathrm{SS}$ column chromatography $(3 \mathrm{~cm} \times 21 \mathrm{~cm})$ with $\mathrm{H}_{2} \mathrm{O}-\mathrm{MeOH}$ to yield 12 (84.2 mg), 16 (103.7 mg), and five subfractions. Fr. 1-1-5-3 (454.4 mg) was successively separated by a Sephadex LH-20 $\left(\mathrm{H}_{2} \mathrm{O}-\mathrm{MeOH}\right)$ and a Chromatorex ODS $\left(\mathrm{H}_{2} \mathrm{O}-\mathrm{MeOH}\right)$ to afford 11 (24.4 mg). From Fr. 1-1-5-5 (59.8 mg), 17 (6.8 mg) was isolated by Chromatorex ODS chromatography $\left(\mathrm{H}_{2} \mathrm{O}-\mathrm{MeOH}\right)$. Purification of 1-1-6 $(102.3 \mathrm{mg})$ by Diaion HP20SS column chromatography $(3 \mathrm{~cm} \times 26 \mathrm{~cm})$ with $0-100 \% \mathrm{MeOH}$ in $\mathrm{H}_{2} \mathrm{O}$ yielded $13(10.7 \mathrm{mg})$. Fractionation of 1-1-7 (120 mg) on a Diaion HP20SS $(2 \mathrm{~cm} \times 17 \mathrm{~cm})$ with $\mathrm{H}_{2} \mathrm{O}-\mathrm{MeOH}$ gave $5(9.3 \mathrm{mg})$ and nine subfractions. Purification of Fr. 1-1-7-2 $(6.3 \mathrm{mg})$ and Fr. 1-1-7-7 $(11.4 \mathrm{mg})$ by a Chromatorex ODS $\left(\mathrm{H}_{2} \mathrm{O}-\mathrm{MeOH}\right)$ furnished $13(1.2 \mathrm{mg})$ and $\mathbf{1 7}(3.2 \mathrm{mg})$, respectively. Fr. 1-1-8 (210.7 mg) was separated by Diaion HP20SS chromatography to yield $8(16.3 \mathrm{mg})$ and five subfractions, and subfraction 1-1-8-1 (59.4 mg) was further subjected to purification using a Sephadex LH $20(2 \mathrm{~cm} \times 16 \mathrm{~cm})$ with $\mathrm{EtOH}-\mathrm{H}_{2} \mathrm{O}$-acetone (1:0:0, 9:1:0, 8:2:0, 6:4:0, 54:36:10, 48:32:20, 36:24:40, 0:50:50, $v / v)$ and then a Chromatorex ODS $\left(\mathrm{H}_{2} \mathrm{O}-\mathrm{MeOH}\right)$ 
to give 14 (39.6 mg). Purification of Fr. 1-1-9 (204.8 mg) by Diaion HP 20SS chromatography $(2 \times 17$ $\mathrm{cm})$ with $\mathrm{H}_{2} \mathrm{O}-\mathrm{MeOH}$ resulted in the isolation of $\mathbf{1 8}(11.4 \mathrm{mg})$.

2-(2,4,6-Trihydroxyphenyl)-4-(3,4,5-trihydroxyphenyl)-3,4-dihydro-2H-1-benzopyran-3,5,7-triol (2R,3R,4S) (13): pale brown amorphous powder; $[\alpha]_{\mathrm{D}}^{20}-15.0(c=0.11, \mathrm{MeOH}) ; \mathrm{UV}(\mathrm{MeOH}) \lambda_{\max }(\log \varepsilon) 270(3.50)$, 234 (4.40), 210 (4.85) nm; CD (MeOH) $\Delta \varepsilon_{227}+0.8, \Delta \varepsilon_{267}+1.2$; IR $v_{\max } 3333,1614,1522,1462,1328 \mathrm{~cm}^{-1}$; HRFABMS $m / z$ 431.0979 [M + H] ${ }^{+}$(calcd for $\left.\mathrm{C}_{21} \mathrm{H}_{19} \mathrm{O}_{10}, 431.0973\right) ;{ }^{1} \mathrm{H}$ - and ${ }^{13} \mathrm{C}-\mathrm{NMR}$ data, see Table 2 .

(-)-Epigallocatechin- $(4 \beta \rightarrow 8,2 \rightarrow O \rightarrow 7)-(-)$-epigallocatechin-4-phloroglucinol (14): pale brown amorphous powder; $[\alpha]_{\mathrm{D}}^{19}+53.1(c=0.14, \mathrm{MeOH}) ; \mathrm{UV}(\mathrm{MeOH}) \lambda_{\max }(\log \varepsilon) 270(3.62), 235(4.39), 214(4.84) \mathrm{nm}$; $\mathrm{CD}(\mathrm{MeOH}) \Delta \varepsilon_{232}+18.9, \Delta \varepsilon_{270}+1.5, \Delta \varepsilon_{283}-1.2 ; \mathrm{IR} v_{\max } 3297,1625,1476,1347 \mathrm{~cm}^{-1} ;$ HRFABMS $\mathrm{m} / z$ $733.1406[\mathrm{M}+\mathrm{H}]^{+}$(calcd for $\left.\mathrm{C}_{36} \mathrm{H}_{29} \mathrm{O}_{17}, 733.1399\right) ;{ }^{1} \mathrm{H}$ - and ${ }^{13} \mathrm{C}-\mathrm{NMR}$ data, see Table 2 .

(-)-Epigallocatechin- $(4 \beta \rightarrow 1,2 \rightarrow O \rightarrow 2)$-phloroglucinol (16): pale yellow amorphous powder; $[\alpha]_{\mathrm{D}}^{19}-6.6$ $(c=0.14, \mathrm{MeOH}) ; \mathrm{UV}(\mathrm{MeOH}) \lambda_{\max }(\log \varepsilon) 270$ (3.62), 235 (4.39), 214 (4.84) nm; CD (MeOH) $\Delta \varepsilon_{216}$ $+4.2, \Delta \varepsilon_{246}+1.2, \Delta \varepsilon_{270}-1.6$; IR $v_{\max } 3297,1625,1476,1347 \mathrm{~cm}^{-1}$; HRFABMS $\mathrm{m} / z 429.0818[\mathrm{M}+\mathrm{H}]^{+}$ (calcd for $\mathrm{C}_{21} \mathrm{H}_{17} \mathrm{O}_{10}, 429.0816$ ); ${ }^{1} \mathrm{H}$ - and ${ }^{13} \mathrm{C}-\mathrm{NMR}$ data, see Table 2.

\subsection{Calculations of ECD Spectra}

A conformational search was performed using the Monte Carlo method with the MMFF94 force field using Spartan'14 (Wavefunction, Irvine, CA, USA). The resulting low-energy conformers within $6 \mathrm{kcal} / \mathrm{mol}$ of the global minimum were optimized at the B3LYP-SCRF/6-31G(d,p) level in MeOH (PCM). The vibrational frequencies were also calculated at the same level to confirm that they were true minima, and no imaginary frequencies were found. The energies, oscillator strengths, and rotational strengths of the low-energy conformers with Boltzmann populations greater than $1 \%$ were calculated using TDDFT at the CAM-B3LYP-SCRF/6-31G(d,p) level in MeOH (PCM). The ECD spectra were simulated by overlapping Gaussian functions with a $0.3 \mathrm{eV}$ exponential half-width, and red-shifted by $25 \mathrm{~nm}$. The calculated data for each conformer were averaged according to the Boltzmann distribution theory at $298 \mathrm{~K}$ based on their relative Gibbs free energies. All DFT calculations were performed using Gaussian 09 [48].

\section{Conclusions}

The proanthocyanidins of E. sinica are mainly composed of oligomers, and in this study, the oligomers were separated and chemically characterized for the first time. Acid-catalyzed degradation with mercaptoethanol and phloroglucinol afforded 18 products, among which seven were previously unreported compounds. Epigallocatechin was the major extension unit, and catechin and A-type prodelphinidin dimers were identified as terminal units. The new compounds were characterized by spectroscopic analyses, and the stereochemistry of the trimeric products was determined with the aid of TDDFT calculations of the ECD spectra. Since E. sinica is one of the most important crude drugs in East Asia, and proanthocyanidins are major constituents with a comparable abundance to alkaloids, our results provide important insights into the molecular basis of traditional medicine.

Supplementary Materials: The following are available online: Figure S1: Fractionation of proanthocyanidin oligomers of E. sinica, Figures S2-S4, Scheme for isolation of acid-catalyzed degradation products of E. sinica, Figures S5-S53, IR, ${ }^{1} \mathrm{H}-\mathrm{NMR},{ }^{13} \mathrm{C}-\mathrm{NMR},{ }^{1} \mathrm{H}-{ }^{1} \mathrm{H}$ COSY, HSQC, HMBC, and NOE spectra of compounds 1, 2, 3, 7, 13, 14, and 16 .

Acknowledgments: This work was supported by the Japan Society for the Promotion of Science KAKENHI (Grant No. 17K08338 and 26460125). The authors are grateful to N. Tsuda, K. Chifuku, and H. Iwata at the Center for Industry, University and Government Cooperation, Nagasaki University, for recording the NMR and MS data. In addition, J.O. would like to express her sincere thanks to the Japanese Government (MEXT) Scholarships for doctoral scholarships. We thank Edanz Group (www.edanzediting.com/ac) for editing a draft of this manuscript. The computation was partly carried out using the computer facilities at the Research Institute for Information Technology, Kyushu University. 
Author Contributions: T.T. and Y.M. conceived and designed the experiments, and analyzed the data; J.O. performed the experiments and analyzed the data. Y.M. performed the calculation and analyzed the ECD spectra of compound 3. J.O., Y.M., Y.S., and T.T. all wrote the paper.

Conflicts of Interest: The authors declare no conflict of interest.

\section{References}

1. Zhu, Y. Chinese Materia Medica: Chemistry, Pharmacology and Applications; Harwood Academic Publisher: Amsterdam, Netherlands, 1998; pp. 48-51, ISBN 90-5702-285-0.

2. World Health Organization. WHO Monographs on Selected Medicinal Plants; World Health Organization: Geneva, Switzerland, 1999; Volume 1, pp. 145-153, ISBN 9241545178.

3. Wang, L.; Kakiuchi, N.; Mikage, M. Studies of Ephedra plants in Asia. Part 6: Geographical changes of anatomical features and alkaloids content of Ephedra sinica. J. Nat. Med. 2009, 64, 63-69. [CrossRef] [PubMed]

4. Liu, Y.; Sheu, S.; Chiou, S.; Chang, H.; Chen, Y. A comparative study of commercial samples of Ephedrae herba. Planta Med. 1993, 59, 376-378. [CrossRef] [PubMed]

5. Westfall, T.; Westfall, D. Adrenergic agonists and antagonists. In Goodman $\mathcal{E}$ Gilman's the Pharmacological Basis of Therapeutics, 12th ed.; Brunton, L., Chabner, B., Knollman, B., Eds.; McGraw-Hill Medical: New York, NY, USA, 2011; pp. 277-333, ISBN 978-0-07-162442-8.

6. Caveney, S.; Charlet, D.; Freitag, H.; Maier-Stolte, M.; Starratt, A. New observations on the secondary chemistry of world Ephedra (Ephedraceae). Am. J. Bot. 2001, 88, 1199-1208. [CrossRef] [PubMed]

7. De Bruyne, T.; Pieters, L.; Delstra, H.; Vlietinck, A. Condensed vegetable tannins: Biodiversity in structure and biological activities. Biochem. Syst. Ecol. 1999, 27, 445-459. [CrossRef]

8. Magos, G.; Mateos, J.; Páez, E.; Fernández, G.; Lobato, C.; Márquez, C.; Enríquez, R. Hypotensive and vasorelaxant effects of the procyanidin fraction from Guazuma ulmifolia bark in normotensive and hypertensive rats. J. Ethnopharm. 2008, 117, 58-68. [CrossRef] [PubMed]

9. Sanz, M.; Terencio, M.; Paya, M. Isolation and hypotensive activity of a polymeric procyanidin fraction from Pistacia lentiscus L. Pharmazie 1992, 47, 466-467. [PubMed]

10. Zeng, X.; Ma, Y.; Gu, H.; Gu, Y.; Huang, M. The effect of oligomeric proanthocyanidin on airway microenvironment in asthma. Eur. Respir. J. 2016, 48 (Suppl. S60). [CrossRef]

11. Zhou, D.; Fang, S.; Zou, C.; Zhang, Q.; Gu, W. Proanthocyanidin from grape seed extract inhibits airway inflammation and remodeling in a murine model of chronic asthma. Nat. Prod. Commun. 2015, 10, 257-262. [PubMed]

12. Zang, X.; Shang, M.; Xu, F.; Liang, J.; Wang, X.; Mikage, M.; Cai, S. A-Type proanthocyanidins from the stems of Ephedra sinica (Ephedraceae) and their antimicrobial activities. Molecules 2013, 18, 5172-5189. [CrossRef] [PubMed]

13. Bagheri-Gavkosh, S.; Bigdeli, M.; Shams-Ghahfarokhi, M.; Razzaghi-Abyaneh, M. Inhibitory effects of Ephedra major host on Aspergillus parasiticus growth and aflatoxin production. Mycopathologia 2009, 168, 249-255. [CrossRef] [PubMed]

14. Okawa, M.; Kinjo, J.; Nohara, T.; Ono, M. DPPH (1,1-diphenyl-2-picrylhydrazyl) radical scavenging activity of flavonoids obtained from some medicinal plants. Biol. Pharm. Bull. 2001, 24, 1202-1205. [CrossRef] [PubMed]

15. Kim, I.; Park, Y.J.; Yoon, S.; Lee, H. Ephedrannin A and B from roots of Ephedra sinica inhibit lipopolysaccharideinduced inflammatory mediators by suppressing nuclear factor-kB activation in RAW 264.7 macrophages. Int. Immunopharmacol. 2010, 10, 1616-1625. [CrossRef] [PubMed]

16. Kim, S.; Son, K.; Chang, H.; Kang, S.; Kim, H. Inhibitory effects of plant extracts on adjuvant-induced arthritis. Arch. Pharm. Res. 1997, 20, 313-317. [CrossRef] [PubMed]

17. Chen, R.; Zhu, G.; Xu, Z. Effect of different extracts from Ephedra on cell immunity. J. Nanjing Univ. Tradit. Chin. Med. 2001, 4, 15.

18. Li, L.; Yu, C.; Ying, H.; Yu, J. Antiviral effects of modified Dingchuan decoction against respiratory syncytial virus infection in vitro and in an immunosuppressive mouse model. J. Ethnopharm. 2013, 147, 238-244. [CrossRef] [PubMed]

19. Nam, N.; Lee, C.; Hong, D.; Kim, H.; Bae, K.; Ahn, B. Antiinvasive, antiangiogenic and antitumor activity of Ephedra sinica extract. Phytother. Res. 2003, 17, 70-76. [CrossRef] [PubMed] 
20. Lee, M.; Cheng, W.; Che, C.; Hsieh, D. Cytotoxicity assessment of Ma-huang (Ephedra) under different conditions of preparation. Toxicol. Sci. 2000, 56, 424-430. [CrossRef] [PubMed]

21. Tao, H.; Wang, L.; Cui, Z.; Zhao, D.; Liu, Y. Dimeric proanthocyanidins from the roots of Ephedra sinica. Planta Med. 2008, 74, 1823-1825. [CrossRef] [PubMed]

22. Yokozawa, T.; Fujioka, K.; Oura, H.; Tanaka, T.; Nonaka, G.; Nishioka, I. Decrease in uremic toxins, a newly found beneficial effect of Ephedrae Herba. Phytother. Res. 1995, 9, 382-384. [CrossRef]

23. Wang, G.Z.; Hikokichi, O. Experimental study in treating chronic renal failure with dry extract and tannins of Herba Ephedra. Zhongguo Zhong Xi Yi Jie He Za Zhi 1994, 14, 485-488. [PubMed]

24. King, F.; Clark-Lewis, J.; Forbes, W. The chemistry of extractives from hardwoods. Part XXV. (-)-epiAfzelechin, a new member of the catechin series. J. Chem. Soc. 1955, 2948-2956. [CrossRef]

25. Hikino, H.; Takahashi, M.; Konno, C. Structure of ephedrannin A, a hypotensive principle of Ephedra roots. Tetrahedron Lett. 1982, 23, 673-676. [CrossRef]

26. Hikino, H.; Shimoyama, N.; Kasahara, Y.; Takahashi, M.; Konno, C. Structures of mahuannin A and B, hypotensive principles of Ephedra roots. Heterocycles 1982, 19, 1381-1384. [CrossRef]

27. Kasahara, H.; Hikino, H. Structure of mahuannin D, a hypotensive principle of Ephedra roots. Heterocycles 1983, 20, 1953-1956. [CrossRef]

28. Nonaka, G.; Morimoto, S.; Kinjo, J.; Nohara, T.; Nishioka, I. Tannins and related compounds L. Structures of proanthocyanidin A-1 and related compounds. Chem. Pharm. Bull. 1987, 35, 149-155. [CrossRef]

29. Kennedy, J.; Jones, G. Analysis of proanthocyanidin cleavage products following acid-catalysis in the presence of excess phloroglucinol. J. Agric. Food Chem. 2001, 49, 1740-1746. [CrossRef] [PubMed]

30. Yanagida, A.; Shoji, T.; Shibusawa, Y. Separation of proanthocyanidins by degree of polymerization by means of size-exclusion chromatography and related techniques. J. Biochem. Biophys. Methods 2003, 56, 311-322. [CrossRef]

31. Kolodziej, H. ${ }^{1} \mathrm{H}$ NMR spectral studies of procyanidin derivatives: Diagnostic ${ }^{1} \mathrm{H}$ NMR parameters applicable to the structural elucidation of oligomeric procyanidins. In Plant Polyphenols-Synthesis, Properties, Significance; Hemingway, R., Laks, P.E., Eds.; Plenum Press: New York, NY, USA, 1992; pp. 295-319, ISBN 978-1-4615-3476-1.

32. Porter, L.; Newman, R.; Foo, L.; Wong, H.; Hemingway, R. Polymeric proanthocyanidins. ${ }^{13}$ C-NMR studies of procyanidins. J. Chem. Soc. Perkin Trans. 1 1982, 1217-1221. [CrossRef]

33. Foo, L.; Newman, R.; Waghorn, G.; McNabb, W.; Ulyatt, M. Proanthocyanidins from Lotus corniculatus. Phytochemistry 1996, 41, 617-624. [CrossRef]

34. Chai, W.; Shi, Y.; Feng, H.; Qiu, L.; Zhou, H.; Deng, Z.; Yan, C.; Chen, X. NMR, HPLC-ESI-MS, and MALDI-TOF MS analysis of condensed tannins from Delonix regia (Bojer ex Hook.) Raf. and their bioactivities. J. Agric. Food Chem. 2012, 60, 5013-5022. [CrossRef] [PubMed]

35. Kusano, R.; Ogawa, S.; Matsuo, Y.; Tanaka, T.; Yazaki, Y.; Kouno, I. $\alpha$-amylase and lipase inhibitory activity and structural characterization of acacia bark proanthocyanidins. J. Nat. Prod. 2011, 74, 119-128. [CrossRef] [PubMed]

36. Bautista-Ortin, A.; Molero, N.; Marín, F.; Ruiz-García, Y.; Gómez-Plaza, E. Reactivity of pure and commercial grape skin tannins with cell wall material. Eur. Food Res. Technol. 2015, 240, 645-654. [CrossRef]

37. Tanaka, T.; Takahashi, R.; Kouno, I.; Nonaka, G. Chemical evidence for the de-astringency (insolubilization of tannins) of persimmon fruit. J. Chem. Soc. Perkin Trans. 1 1994, 3013-3022. [CrossRef]

38. Tanaka, T.; Kondou, K.; Kouno, I. Oxidation and epimerization of epigallocatechin in banana fruits. Phytochemistry 2000, 53, 311-316. [CrossRef]

39. Steynberg, J.; Brandt, E.; Hoffman, M.; Ferreira, D. Conformations of proanthocyanidins. In Plant Polyphenols-Synthesis, Properties, Significance; Hemingway, R., Laks, P.E., Eds.; Plenum Press: New York, NY, USA, 1992; pp. 501-519, ISBN 978-1-4615-3476-1.

40. Slade, D.; Ferreira, D.; Marais, J.P.J. Circular dichroism, a powerful tool for the assessment of absolute configuration of flavonoids. Phytochemistry 2005, 66, 2177-2215. [CrossRef] [PubMed]

41. Esatbeyoglu, T.; Jaschok-Kentner, B.; Wray, V.; Winterhalter, P. Structure elucidation of proanthocyanidin oligomers by low-temperature ${ }^{1} \mathrm{H}$ NMR spectroscopy. J. Agric. Food Chem. 2011, 59, 62-69. [CrossRef] [PubMed] 
42. Nam, J.W.; Phansaklar, R.S.; Lankin, D.C.; McAlpine, J.B.; Leme-Kraus, A.A.; Vidal, C.M.; Gan, L.S.; Bedran-Russo, A.; Chen, S.N.; Pauli, G.F. Absolute configuration of native oligomeric proanthocyanidins with dentin biomodification potency. J. Org. Chem. 2017, 82, 1316-1329. [CrossRef] [PubMed]

43. Barrett, M.; Klyne, W.; Scopes, P.; Fletcher, A.; Porter, L.; Haslam, E. Plant proanthocyanidins. Part 6. Chiroptical studies. Part 95. Circular dichroism of procyanidins. J. Chem. Soc. Perkin Trans. 1 1979, 2375-2377. [CrossRef]

44. Yu, R.J.; Liu, H.B.; Yu, Y.; Liang, L.; Xu, R.; Liang, C.; Tang, J.S.; Yao, X.S. Anticancer activities of proanthocyanidins from the plant Urceola huaitingii and their synergistic effects in combination with chemotherapeutics. Fitoterapia 2016, 112, 175-182. [CrossRef] [PubMed]

45. Burger, J.; Kolodziej, H.; Hemingway, R.; Steynberg, J.; Young, D.; Ferreira, D. Oligomeric flavonoids. Part 15a. Base-catalyzed pyran rearrangements of procyanidin B-2, and evidence for the oxidative transformation of B- to A-type procyanidins. Tetrahedron 1990, 46, 5733-5740. [CrossRef]

46. Koerner, J.; Hsu, V.; Lee, J.K. Determination of proanthocyanidin A2 content in phenolic polymer isolates by reversed-phase high-performance liquid chromatography. J. Chromatogr. A 2009, 1216, 1403-1409. [CrossRef] [PubMed]

47. Cronjé, A.; Burger, J.; Brandt, E.; Kolodziej, H.; Ferreira, D. Assessment of 3,4-trans and 3,4-cis relative configurations in the A-series of 4,8-linked proanthocyanidins. Tetrahedron Lett. 1990, 31, 3789-3792. [CrossRef]

48. Frisch, M.J.; Trucks, G.W.; Schlegel, H.B.; Scuseria, G.E.; Robb, M.A.; Cheeseman, J.R.; Scalmani, G.; Barone, V.; Mennucci, B.; Petersson, G.A.; et al. Gaussian 09, Revision D.01; Gaussian, Inc.: Wallingford, CT, USA, 2013.

Sample Availability: Samples of compounds 1-18 are all available from the authors.

(C) 2017 by the authors. Licensee MDPI, Basel, Switzerland. This article is an open access article distributed under the terms and conditions of the Creative Commons Attribution (CC BY) license (http://creativecommons.org/licenses/by/4.0/). 